\title{
Reusable Monolithic Nanoporous Graphite-supported Nanocatalysts (Fe, Au, Pt, Pd, Ni and Rh) from Pyrolysis and Galvanic Transmetalation of Ferrocene-Based Polyamide Aerogels
}

Adnan M. Saeed, Clarissa A. Wisner, Suraj Donthula, Hojat Majedi Far, Chariklia SotiriouLeventis $^{*}$ and Nicholas Leventis ${ }^{*}$

Department of Chemistry, Missouri University of Science and Technology, Rolla, MO 65409, U.S.A.E-mail addresses: leventis@mst.edu; cslevent@mst.edu

\section{Supporting Information}

Page No.

Index

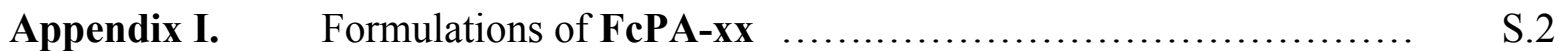

Appendix II. Materials characterization data for:

......FcPA-xx; FcPA-15 after pyrolysis; and $\boldsymbol{t m}$-M@C .......... S.3 - S.5

Appendix III. Porous structure analysis of all samples: $\mathrm{N}_{2}$ sorption data ....... S.6 - S.10

Appendix IV. Analysis of the FcPA-xx skeletal frameworks: SAXS data........ S.11 - S.12

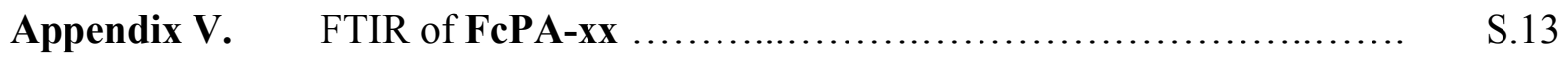

Appendix VI. Additional PXRD data related to transmetalation, and.....

...... removal of $\mathrm{Fe}(0)$ from $\mathbf{F e} @ \mathbf{C}$ with $\mathrm{HCl} \ldots \ldots \ldots \ldots \ldots . . . . . . . .5 .14$ - S.16

Appendix VII. Additional TEM of Fe@C and $\boldsymbol{t m - M @ C ~ . . . . . . . . . . . . . . . . . . . . . . . ~ S . 1 7 ~ - ~ S . 1 8 ~}$

Appendix VIII. Raman of FcPA-15 after pyrolysis at different temperatures ....... S.19

Appendix IX. Data from catalysis using Fe@C and $\boldsymbol{t}$. $-\mathbf{M} @ \mathbf{C}$ as catalysts ...... S.20 - S.29 


\section{Appendix I. Formulations of FcPA-xx}

Table S.1. Formulations and gelation times of FcPA-xx aerogels

\begin{tabular}{|c|c|c|c|c|c|c|c|c|c|c|c|c|}
\hline \multirow{2}{*}{ Sample ${ }^{a}$} & \multicolumn{4}{|c|}{$\mathrm{Fc}(\mathrm{COOH})_{2}$} & \multicolumn{2}{|c|}{ Desmodur RE } & \multicolumn{3}{|c|}{ TIPM } & \multicolumn{2}{|c|}{ DMF } & \multirow{2}{*}{$\frac{\text { gelation time }}{90{ }^{\circ} \mathrm{C}}$} \\
\hline & $\begin{array}{c}\text { mass } \\
(\mathrm{g})\end{array}$ & $\begin{array}{c}\text { volume }^{b} \\
(\mathrm{~mL})\end{array}$ & $\mathrm{mmol}$ & $\begin{array}{c}C \\
(\mathrm{M})\end{array}$ & $\begin{array}{c}\text { volume } \\
(\mathrm{mL})\end{array}$ & $\begin{array}{c}\operatorname{mass}^{\mathrm{c}} \\
(\mathrm{g})\end{array}$ & $\begin{array}{c}\operatorname{mass}^{\mathrm{d}} \\
(\mathrm{g})\end{array}$ & $\mathrm{mmol}$ & $\begin{array}{c}C \\
(\mathrm{M})\end{array}$ & $\begin{array}{c}\text { mass } \\
(\mathrm{g})\end{array}$ & $\begin{array}{c}\text { volume } \\
(\mathrm{mL})\end{array}$ & \\
\hline FcPA-05 & 0.411 & 0.244 & 1.5 & 0.093 & 1.33 & 1.359 & 0.367 & 1.00 & 0.062 & 13.79 & 14.52 & $\sim 3 \mathrm{~h}$ \\
\hline FcPA-10 & 0.411 & 0.244 & 1.5 & 0.190 & 1.33 & 1.359 & 0.367 & 1.00 & 0.126 & 6.01 & 6.32 & $2 \mathrm{~h} 30 \mathrm{~min}$ \\
\hline FcPA-15 & 0.411 & 0.244 & 1.5 & 0.289 & 1.33 & 1.359 & & 1.00 & 0.193 & 3.41 & 3.60 & $2 \mathrm{~h} 15 \mathrm{~min}$ \\
\hline FcPA-20 & 0.411 & 0.244 & 1.5 & 0.394 & 1.33 & 1.359 & 0.367 & 1.00 & 0.262 & 2.12 & 2.23 & $\sim 2 \mathrm{~h}$ \\
\hline FcPA-25 & 0.411 & 0.244 & 1.5 & 0.502 & 1.33 & 1.359 & 0.367 & 1.00 & 0.335 & 1.34 & 1.41 & $1 \mathrm{~h} 45 \mathrm{~min}$ \\
\hline
\end{tabular}

${ }^{a}$ Numerical extensions in the sample names designate the weight percent of total monomer $\left(\mathrm{Fc}(\mathrm{COOH})_{2}+\mathrm{TIPM}\right)$ in the sol. ${ }^{\mathrm{b}}$ The volume of $\mathrm{Fc}(\mathrm{COOH})_{2}$ was calculated based on its density measured with helium pycnometry $\left(1.685 \mathrm{~g} \mathrm{~cm}^{-3}\right)$. ${ }^{\mathrm{c}}$ The mass of commercial Desmodur RE was calculated based on its density that in turn was measured in our laboratory $\left(1.022 \mathrm{~g} \mathrm{~cm}^{-3}\right){ }^{\mathrm{d}}$ The mass of TIPM in Desmodur RE was calculated based on the weight percent of monomer (27\%) given by the manufacturer. 


\section{Appendix II. Materials characterization data for:}

\section{FcPA-xx; FcPA-15 after pyrolysis; and, tm-M@C (M: Au, Pt, Pd)}

Table S.2. Characterization of FcPA-xx aerogels

\begin{tabular}{|c|c|c|c|c|c|c|c|c|c|c|c|c|c|}
\hline \multirow[t]{2}{*}{$\mathbf{x x}$} & \multirow[t]{2}{*}{$\begin{array}{c}\text { linear } \\
\text { shrinkage } \\
(\%)^{a, b}\end{array}$} & \multirow[t]{2}{*}{$\begin{array}{c}\text { bulk } \\
\text { density, } \\
\rho_{\mathrm{b}}\left(\mathrm{g} \mathrm{cm}^{-3}\right)^{\mathrm{a}}\end{array}$} & \multirow[t]{2}{*}{$\begin{array}{c}\text { skeletal } \\
\text { density, } \\
\rho_{\mathrm{s}}\left(\mathrm{g} \mathrm{cm}^{-3}\right)^{\mathrm{c}}\end{array}$} & \multirow[t]{2}{*}{$\Pi^{d}$} & \multicolumn{3}{|c|}{$\begin{array}{l}\text { specific pore volume } \\
\left(\mathrm{cm}^{3} \mathrm{~g}^{-1}\right)\end{array}$} & \multirow{2}{*}{$\begin{array}{c}\text { BET } \\
\text { surface } \\
\text { area, } \sigma \\
\left(\mathrm{m}^{2} \mathrm{~g}^{-1}\right)\end{array}$} & \multicolumn{2}{|c|}{$\begin{array}{c}\text { average pore } \\
\text { diameter } \\
(\mathrm{nm})\end{array}$} & \multicolumn{3}{|c|}{$\begin{array}{l}\text { particle radius } \\
(\mathrm{nm})\end{array}$} \\
\hline & & & & & $V_{\text {Total }}{ }^{\mathrm{e}}$ & $V_{1.7-300 \_\mathrm{nm}}$ & $300 \mathrm{~nm}^{\mathrm{g}}$ & & $\begin{array}{l}4 V / \sigma^{\mathrm{h}} \\
\text { method }\end{array}$ & $\begin{array}{r}\mathrm{BJH}^{\mathrm{I}} \\
\text { method }\end{array}$ & $r^{\mathrm{j}}$ & $R_{1}^{\mathrm{k}}$ & $R_{2}{ }^{1}$ \\
\hline 05 & $41.21 \pm 0.50$ & $0.123 \pm 0.006$ & $1.472 \pm 0.004$ & 92 & 7.451 & 1.448 & 6.003 & 456 & $14[65]$ & $42[63]$ & 4.47 & $4.98 \pm 0.45$ & $29.11 \pm 0.96$ \\
\hline 10 & $39.32 \pm 0.09$ & $0.202 \pm 0.008$ & $1.342 \pm 0.006$ & 85 & 4.205 & 2.360 & 1.845 & 381 & $25[44]$ & $32[14]$ & 5.87 & $6.57 \pm 0.32$ & $25.03 \pm 0.37$ \\
\hline 15 & $38.11 \pm 0.03$ & $0.340 \pm 0.004$ & $1.333 \pm 0.005$ & 74 & 2.191 & 0.983 & 1.213 & 308 & 14 [29] & $20[12]$ & 7.31 & $3.94 \pm 0.45$ & $21.97 \pm 0.45$ \\
\hline 20 & $37.52 \pm 0.70$ & $0.401 \pm 0.003$ & $1.363 \pm 0.003$ & 70 & 1.760 & 0.829 & 0.931 & 276 & $12[26]$ & $16[4.8]$ & 7.97 & $2.85 \pm 0.15$ & $19.13 \pm 0.19$ \\
\hline 25 & $35.44 \pm 0.10$ & $0.490 \pm 0.007$ & $1.341 \pm 0.005$ & 63 & 1.295 & 0.719 & 0.576 & 258 & $11[20]$ & $13[4.7]$ & 8.67 & $5.66 \pm 1.44$ & $17.48 \pm 0.37$ \\
\hline
\end{tabular}

${ }^{\mathrm{a}}$ Average of 3 samples. ${ }^{\mathrm{b}}$ Linear shrinkage $=100 \times($ mold diameter - sample diameter $) /($ mold diameter $)$. ${ }^{\mathrm{c}}$ Single sample, average of 50 measurements. ${ }^{\mathrm{d}}$ Porosity (percent of empty space): $\Pi=100 \times\left(\rho_{\mathrm{s}}-\rho_{\mathrm{b}}\right) / \rho_{\mathrm{s}}$. ${ }^{\mathrm{e}}$ Calculated via $V_{\text {Total }}=\left(1 / \rho_{\mathrm{b}}\right)-\left(1 / \rho_{\mathrm{s}}\right)$. ${ }^{\mathrm{f}}$ Cumulative volume of pores between $1.7 \mathrm{~nm}$ and $300 \mathrm{~nm}$ from $\mathrm{N}_{2}$-sorption data and the BJH desorption method. ${ }^{\mathrm{g}} V_{>300 \mathrm{~nm}}=V_{\text {Total }}-V_{1.7-300 \mathrm{~nm}}{ }^{\mathrm{h}}$ For the first number (outside the brackets), $V$ was set equal to the maximum volume of $\mathrm{N}_{2}$ absorbed along the isotherm at $\mathrm{P} / \mathrm{Po} \rightarrow 1.0$; for the number in [brackets], $V$ was taken equal to $V_{\text {Total }}=\left(1 / \rho_{\mathrm{b}}\right)-\left(1 / \rho_{\mathrm{s}}\right)$. ${ }^{\mathrm{i}}$ From the BJH plots: first numbers are peak maxima; numbers in (parentheses) are full widths at half maxima. ${ }^{\mathrm{j}}$ Particle radius, $r=3 /\left(\rho_{\mathrm{s}} \times \sigma\right) ;{ }^{\mathrm{k}} R_{1}$ : radius of primary particles from SAXS; ${ }^{1} R_{2}:$ radius of secondary particles from SAXS. 
Table S.3. Characterization of the product from pyrolysis of FcPA-15 at different temperatures

\begin{tabular}{|c|c|c|c|c|c|c|c|c|c|c|c|}
\hline $\begin{array}{c}\text { Pyrolysis temperature } \\
\text { of } \\
\text { FcPA-15 } \\
\left({ }^{\circ} \mathrm{C}\right)\end{array}$ & $\begin{array}{l}\text { linear } \\
\text { shrinkage } \\
(\%)^{a, b}\end{array}$ & $\begin{array}{c}\text { bulk } \\
\text { density, } \\
\rho_{\mathrm{b}}\left(\mathrm{g} \mathrm{cm}^{-3}\right)^{\mathrm{a}}\end{array}$ & $\begin{array}{c}\text { skeletal } \\
\text { density, } \\
\rho_{\mathrm{s}}\left(\mathrm{g} \mathrm{cm}^{-3}\right)^{\mathrm{c}}\end{array}$ & $\Pi^{d}$ & $V_{\text {Total }}{ }^{\mathrm{e}}$ & $\begin{array}{l}\text { ific pore } \\
\left(\mathrm{cm}^{3} \mathrm{~g}^{-}\right.\end{array}$ & $300 \mathrm{~nm}^{\mathrm{g}}$ & $\begin{array}{c}\text { BET } \\
\text { surface } \\
\text { area, } \sigma \\
\left(\mathrm{m}^{2} \mathrm{~g}^{-1}\right)\end{array}$ & \multicolumn{2}{|c|}{$\begin{array}{l}\text { average pore } \\
\text { diameter } \\
(\mathrm{nm})\end{array}$} & $\begin{array}{c}\text { particle } \\
\text { radius } \\
(\mathrm{nm}) \\
r^{\mathrm{j}} \\
\end{array}$ \\
\hline $800(\mathbf{F e} @ \mathbf{C})$ & $68.24 \pm 0.50$ & $0.286 \pm 0.004$ & $2.400 \pm 0.004$ & 88 & 3.080 & 0.705 & 2.375 & 369 & $9[33]$ & $18[10]$ & 3.38 \\
\hline $\mathbf{F e} @ \mathbf{C H C l}$ treated & $68.33 \pm 0.16$ & $0.263 \pm 0.010$ & $1.704 \pm 0.006$ & 85 & 3.221 & 0.769 & 2.452 & 282 & $9[45]$ & $16[9.5]$ & 6.24 \\
\hline 1000 & $69.10 \pm 0.02$ & $0.812 \pm 0.008$ & $1.890 \pm 0.006$ & 53 & 0.702 & 0.238 & 0.464 & 235 & $5[12]$ & $4[0.28]$ & 6.75 \\
\hline 1200 & $83.42 \pm 0.50$ & $0.720 \pm 0.004$ & $1.491 \pm 0.005$ & 51 & 0.718 & 0.562 & 0.156 & 234 & $10[13]$ & $16[1.88]$ & 8.60 \\
\hline 1400 & $86.02 \pm 0.50$ & $0.981 \pm 0.003$ & $2.149 \pm 0.030$ & 54 & 0.554 & 0.227 & 0.327 & 84 & $11[26]$ & $13[2.63]$ & 16.6 \\
\hline
\end{tabular}

${ }^{\mathrm{a}}$ Average of 3 samples. ${ }^{\mathrm{b}}$ Linear shrinkage $=100 \times($ mold diameter - sample diameter $) /($ mold diameter $) .{ }^{\mathrm{c}}$ Single sample, average of 50 measurements. ${ }^{\mathrm{d}}$ Porosity (percent of empty space): $\Pi=100 \times\left(\rho_{\mathrm{s}}-\rho_{\mathrm{b}}\right) / \rho_{\mathrm{s}}$. ${ }^{\mathrm{e}}$ Calculated via $V_{\text {Total }}=\left(1 / \rho_{\mathrm{b}}\right)-\left(1 / \rho_{\mathrm{s}}\right) .{ }^{\mathrm{f}}$ Cumulative volume of pores between $1.7 \mathrm{~nm}$ and $300 \mathrm{~nm}$ from $\mathrm{N}_{2}$-sorption data and the BJH desorption method. ${ }^{\mathrm{g}} V_{>300 \mathrm{~nm}}=V_{\text {Total }}-V_{1.7-300} \mathrm{~nm} .{ }^{\mathrm{h}}$ For the first number (outside the brackets), $V$ was set equal to the maximum volume of $\mathrm{N}_{2}$ absorbed along the isotherm at $\mathrm{P} / \mathrm{Po} \rightarrow 1.0$; for the number in [brackets], $V$ was taken equal to $V_{\text {Total }}=\left(1 / \rho_{\mathrm{b}}\right)-\left(1 / \rho_{\mathrm{s}}\right)$. (The greater the discrepancy between the two numbers is, the more macroporous the material.) ${ }^{\mathrm{i}}$ From the BJH plots: first numbers are peak maxima; numbers in (parentheses) are full widths at half maxima. ${ }^{\mathrm{j}}$ Particle radius, $r=3 /\left(\rho_{\mathrm{s}} \times \sigma\right)$. 
Table S.4. Characterization of the transmetalation products from $\mathbf{F e} @ \mathbf{C}$

\begin{tabular}{|c|c|c|c|c|c|c|c|c|c|c|c|}
\hline \multirow[t]{2}{*}{$\begin{array}{c}m-\mathbf{M} \mathrm{C} \\
\mathrm{M}\end{array}$} & \multirow[t]{2}{*}{$\begin{array}{c}\text { linear } \\
\text { shrinkage } \\
(\%)^{a, b}\end{array}$} & \multirow[t]{2}{*}{$\begin{array}{c}\text { bulk } \\
\text { density, } \\
\rho_{\mathrm{b}}\left(\mathrm{g} \mathrm{cm}^{-3}\right)^{\mathrm{a}}\end{array}$} & \multirow[t]{2}{*}{$\begin{array}{c}\text { skeletal } \\
\text { density, } \\
\rho_{\mathrm{s}}\left(\mathrm{g} \mathrm{cm}^{-3}\right)^{\mathrm{c}}\end{array}$} & \multirow[t]{2}{*}{$\Pi^{d}$} & \multicolumn{3}{|c|}{$\begin{array}{l}\text { specific pore volume } \\
\qquad\left(\mathrm{cm}^{3} \mathrm{~g}^{-1}\right)\end{array}$} & \multirow{2}{*}{$\begin{array}{c}\text { BET } \\
\text { surface } \\
\text { area, } \sigma \\
\left(\mathrm{m}^{2} \mathrm{~g}^{-1}\right)\end{array}$} & \multicolumn{2}{|c|}{$\begin{array}{l}\text { average pore } \\
\text { diameter } \\
(\mathrm{nm})\end{array}$} & \multirow{2}{*}{$\begin{array}{c}\text { particle } \\
\text { radius } \\
(\mathrm{nm}) \\
r^{\mathrm{j}}\end{array}$} \\
\hline & & & & & $V_{\text {Total }}{ }^{\mathrm{e}}$ & $.7-300 \_n$ & $V_{>300 \mathrm{~nm}}{ }^{\mathrm{g}}$ & & $\begin{array}{l}4 V / \sigma^{\mathrm{h}} \\
\text { method }\end{array}$ & $\begin{array}{l}\mathrm{BJH}^{\mathrm{i}} \\
\text { method }\end{array}$ & \\
\hline $\mathbf{A u}$ & $69.10 \pm 0.02$ & $0.190 \pm 0.003$ & $1.964 \pm 0.038$ & 90 & 4.753 & 0.354 & 4.399 & 101 & 14 [188] & $17[7.86]$ & 15.2 \\
\hline $\mathbf{P t}$ & $70.04 \pm 0.02$ & $0.191 \pm 0.004$ & $1.875 \pm 0.016$ & 89 & 4.701 & 0.284 & 4.417 & 100 & $11[188]$ & $10[1.69]$ & 16.0 \\
\hline Pd & $70.13 \pm 0.05$ & $0.216 \pm 0.008$ & $1.981 \pm 0.018$ & 89 & 4.124 & 0.533 & 3.591 & 133 & 16 [124] & $17[5.07]$ & 11.4 \\
\hline
\end{tabular}

${ }^{\mathrm{a}}$ Average of 3 samples. ${ }^{\mathrm{b}}$ Linear shrinkage $=100 \times($ mold diameter - sample diameter $) /($ mold diameter $)$. ${ }^{\mathrm{c}}$ Single sample, average of 50 measurements. ${ }^{\mathrm{d}}$ Porosity (percent of empty space): $\Pi=100 \times\left(\rho_{\mathrm{s}}-\rho_{\mathrm{b}}\right) / \rho_{\mathrm{s}}$. ${ }^{\mathrm{e}}$ Calculated via $V_{\text {Total }}=\left(1 / \rho_{\mathrm{b}}\right)-\left(1 / \rho_{\mathrm{s}}\right)$. ${ }^{\mathrm{f}}$ Cumulative volume of pores between $1.7 \mathrm{~nm}$ and $300 \mathrm{~nm}$ from $\mathrm{N}_{2}$-sorption data and the BJH desorption method. ${ }^{\mathrm{g}} V_{>300 \mathrm{~nm}}=V_{\text {Total }}-V_{1.7-300} \mathrm{~nm} \cdot{ }^{\mathrm{h}}$ For the first number (outside the brackets), $V$ was set equal to the maximum volume of $\mathrm{N}_{2}$ absorbed along the isotherm at $\mathrm{P} / \mathrm{Po} \rightarrow 1.0$; for the number in [brackets], $V$ was taken equal to $V_{\text {Total }}=\left(1 / \rho_{\mathrm{b}}\right)-\left(1 / \rho_{\mathrm{s}}\right)$. (The greater the discrepancy between the two numbers is, the more macroporous the material. Compare with Fe@C in Table S.3.) ${ }^{\text {i }}$ From the BJH plots: first numbers are peak maxima; numbers in (parentheses) are full widths at half maxima. ${ }^{\mathrm{j}}$ Particle radius, $r=3 /\left(\rho_{\mathrm{s}} \times \sigma\right)$. 
Appendix III. Porous structure analysis of all samples: $\mathbf{N}_{2}$ sorption data
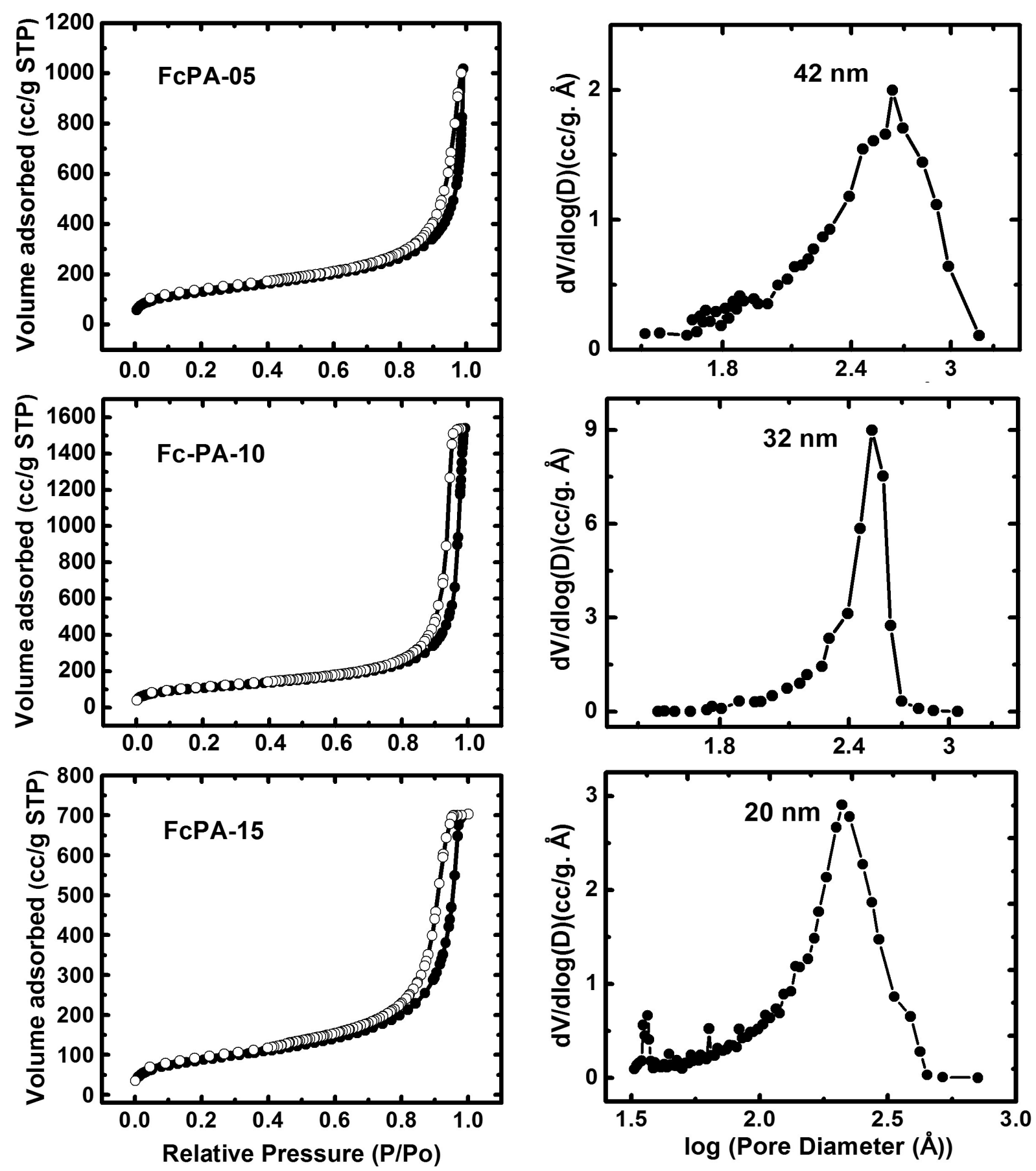

Figure S.1. $\mathrm{N}_{2}$-sorption isotherms and pore size distributions by the BJH method of FcPA-xx aerogels as shown (continued on next page). 
(Continued from previous page)
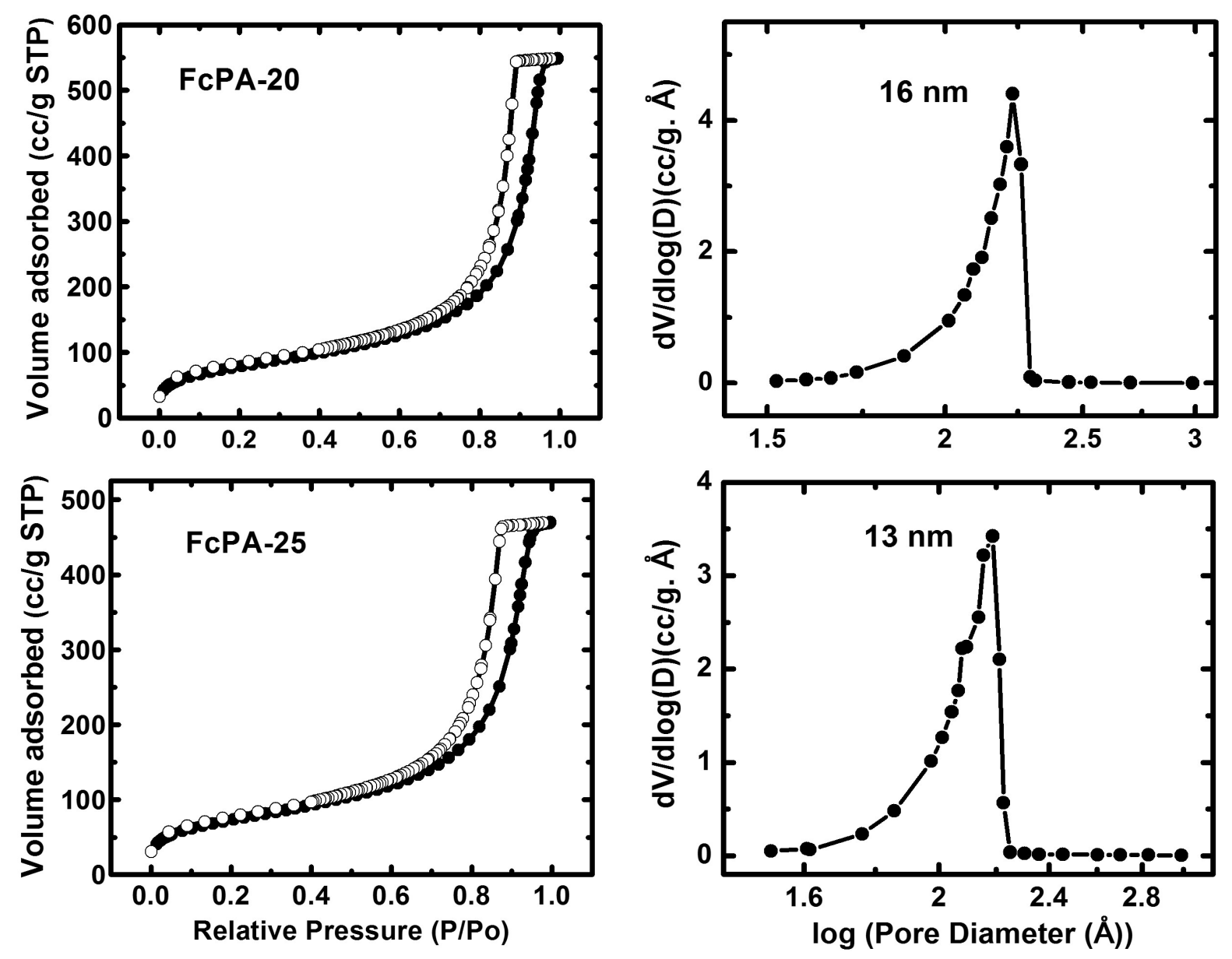

Figure S.1 (Continued). $\mathrm{N}_{2}$-sorption isotherms and pore size distributions by the BJH method of FcPA-xx aerogels as shown. Results are summarized in Table S.2. 

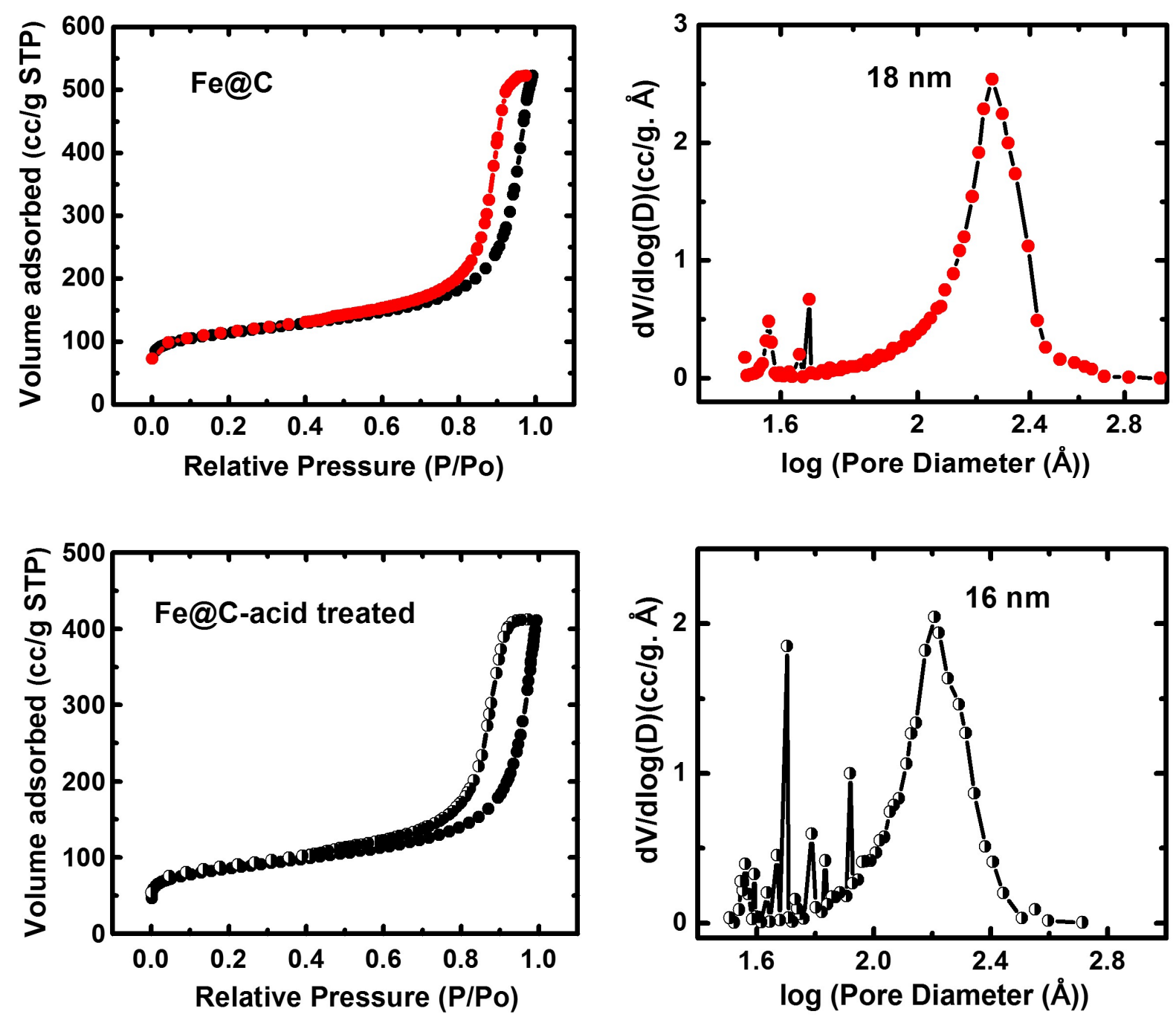

Figure S.2. $\mathrm{N}_{2}$-sorption isotherms and pore size distributions by the BJH method of $\mathbf{F e} @ \mathbf{C}$ (i.e., FcPA-xx aerogels pyrolyzed at $800{ }^{\circ} \mathrm{C} / \mathrm{H}_{2}$ ) and of $\mathbf{F e} @ \mathbf{C}$ after treatment with aq. $\mathrm{HCl}$ to remove Fe nanoparticles. Results are summarized in Table S.3, and in Table 1 of the main article. 

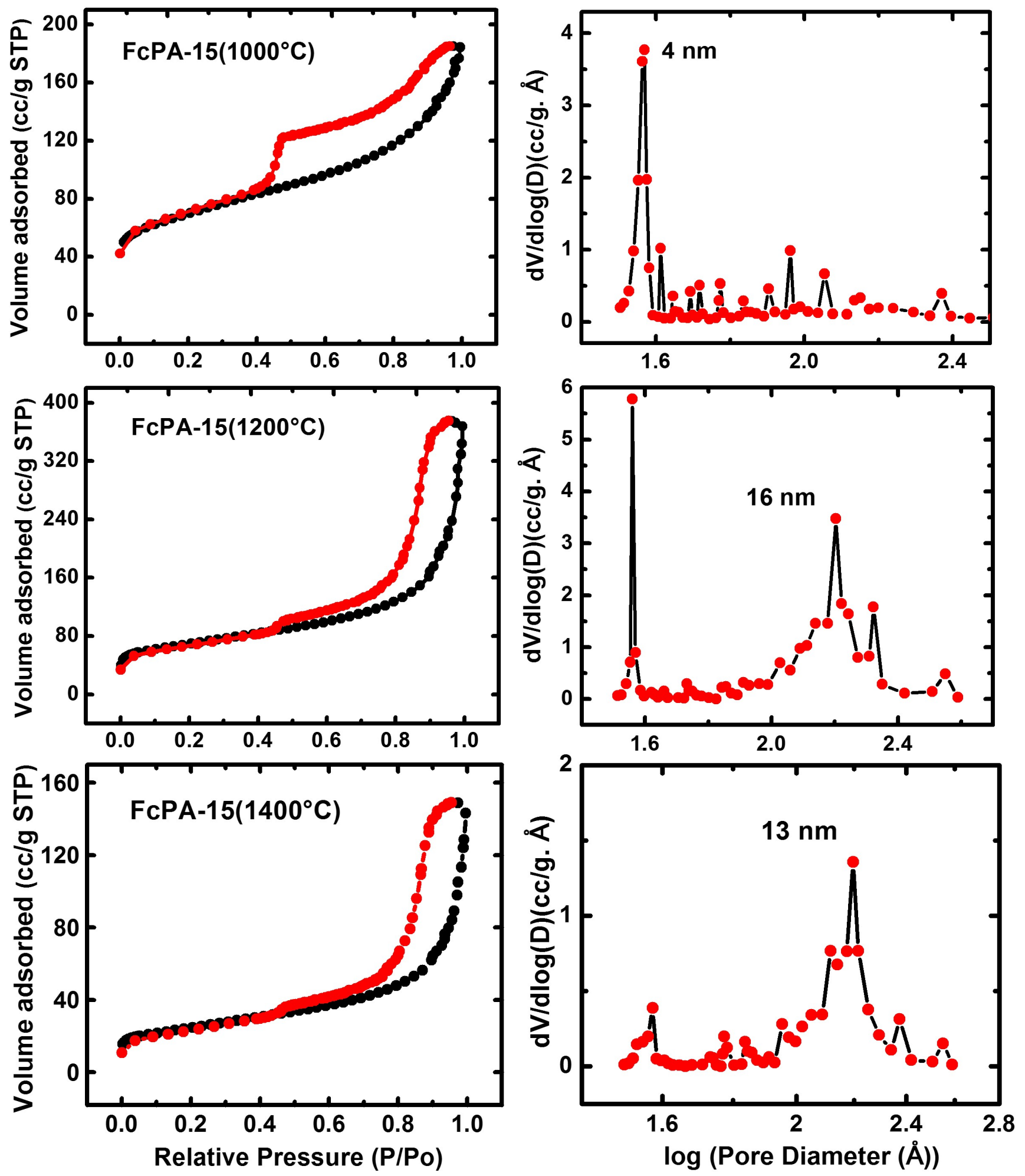

Figure S.3. $\mathrm{N}_{2}$-sorption isotherms and pore size distributions by the BJH method of FcPA-xx aerogels pyrolyzed under $/ \mathrm{H}_{2}$ at the temperatures shown. Results are summarized in Table S.3. 

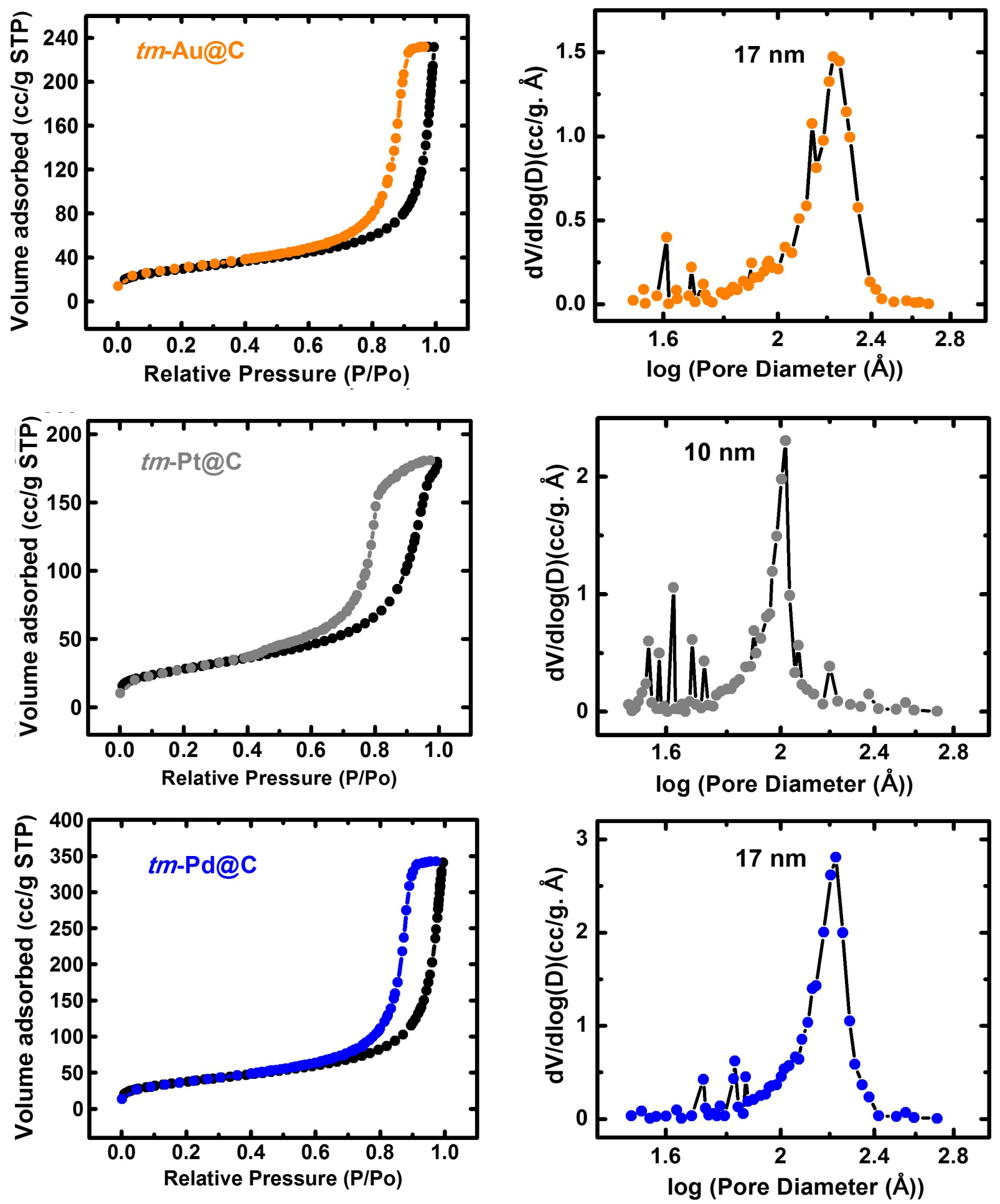

Figure S.4. $\mathrm{N}_{2}$-sorption isotherms and pore size distributions by the BJH method of transmetalated samples as shown. Results are summarized in Table S.4. 
Appendix IV. Analysis of the FcPA-xx skeletal frameworks: SAXS data
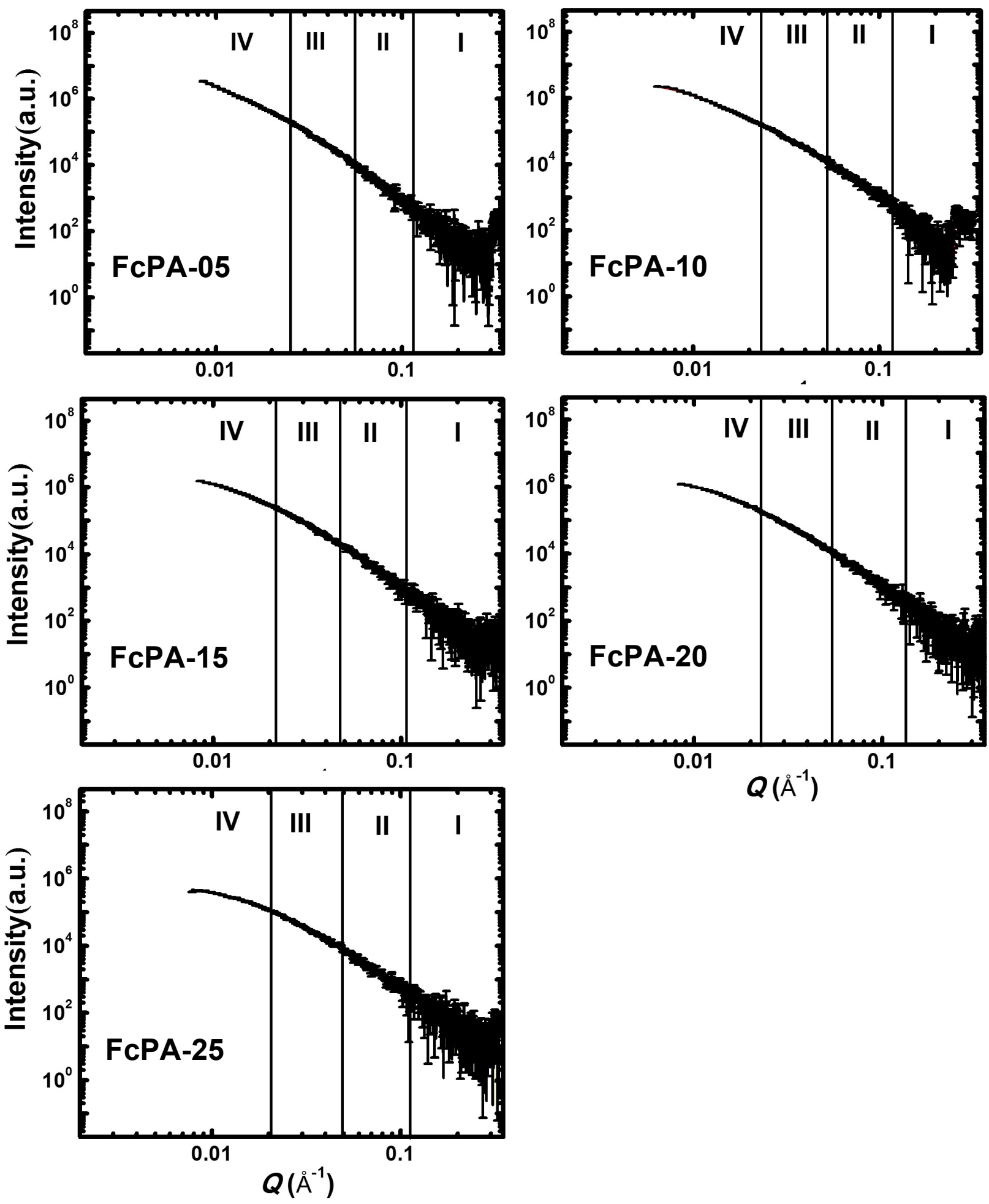

Figure S.5. Small angle X-ray scattering (SAXS) data of FcPA-xx. All data were fitted with two exponentials (Regions I and III) and two Guinier knees (Regions II and IV). Data pertinent to the nanostructures are gathered in Table S.5 below. 
Table S.5. Results from analysis of the SAXS data in Figure S.5 using the Beaucage Unified Model

\begin{tabular}{|l|c|c|c|c|c|c|}
\hline Sample & \multicolumn{3}{|c|}{ Primary Particles } & \multicolumn{3}{c|}{ Secondary Particles } \\
\hline & ${\text { high- } Q \text { slope }^{\mathbf{a}}}$ & $\begin{array}{c}R_{\mathrm{G}}(\mathrm{I}) \\
(\mathrm{nm})\end{array}$ & $\begin{array}{c}\mathbf{b} \\
\text { diameter }^{\mathbf{c}} \\
(\mathrm{nm})\end{array}$ & ${\text { low- } Q \text { slope }^{\mathbf{d}}}^{\mathbf{2}}$ & $\begin{array}{c}R_{\mathrm{G}}(\mathrm{II}) \\
(\mathrm{nm})\end{array}$ & $\begin{array}{c}\text { diameter }^{\mathbf{f}} \\
(\mathrm{nm})\end{array}$ \\
\hline FcPA-05 & $-4.22 \pm 0.14$ & $3.84 \pm 0.35$ & $9.97 \pm 0.91$ & $-3.14 \pm 0.03$ & $22.42 \pm 0.74$ & $58.23 \pm 1.92$ \\
\hline FcPA-10 & $-4.56 \pm 0.08$ & $5.06 \pm 0.25$ & $13.14 \pm 0.64$ & $-2.95 \pm 0.09$ & $20.43 \pm 0.29$ & $50.06 \pm 0.75$ \\
\hline FcPA-15 & $-4.40 \pm 0.10$ & $3.03 \pm 0.35$ & $7.88 \pm 0.91$ & $-3.03 \pm 0.08$ & $16.92 \pm 0.35$ & $43.94 \pm 0.91$ \\
\hline FcPA-20 & $-4.24 \pm 0.29$ & $2.20 \pm 0.12$ & $5.71 \pm 0.31$ & $-3.24 \pm 0.04$ & $14.73 \pm 0.15$ & $38.26 \pm 0.39$ \\
\hline FcPA-25 & $-4.43 \pm 0.14$ & $4.36 \pm 0.88$ & $11.32 \pm 2.28$ & $-3.01 \pm 0.28$ & $13.46 \pm 0.29$ & $34.96 \pm 0.75$ \\
\hline
\end{tabular}

a From power-law Region I. Slopes <-4.0 signify primary particles with density-gradient boundaries.

b Radius of gyration of primary particles, $R_{\mathrm{G}}(\mathrm{I})$, from Region II (first Guinier knee).

c Primary particle diameter $=2\left(R_{\mathrm{G}}(\mathrm{I}) / 0.77\right)$. It is noted that there is a good match of primary particle sizes from SAXS and those calculated from $N_{2}$-soprtion data. For a quick comparison, both values are cited in Table S.2.

d From power-law Region III. If slope $>-3$, mass fractal dimension of secondary particles, $D_{\mathrm{M}}=\mid$ slope|; if slope $<-3$ (as in this case), surface fractal dimension of secondary particles, $D_{\mathrm{s}}=6-\mid$ slope $\mid$.

e Radius of gyration of secondary particles, $R_{\mathrm{G}}(\mathrm{II})$, from Region IV (second Guinier knee).

f $\quad$ Secondary particle diameter $=2\left(R_{\mathrm{G}}(\mathrm{II}) / 0.77\right)$. 


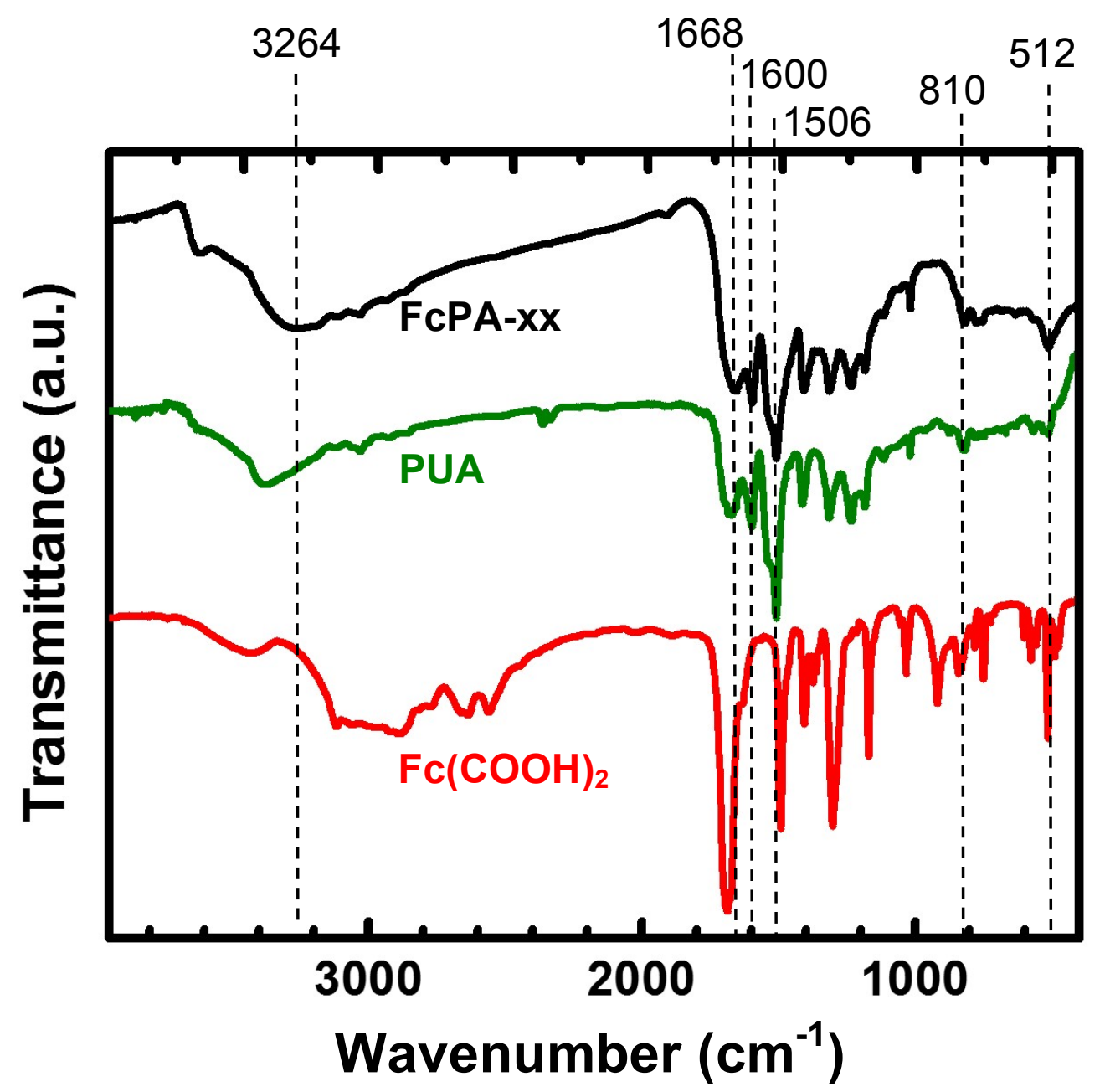

Figure S.6. FTIR of FcPA-xx, TIPM-derived polyurea (PUA) and $\mathrm{Fc}(\mathrm{COOH})_{2}$.

Peak assignment:

NH stretch: $3264 \mathrm{~cm}^{-1}$

$\mathrm{CH}$ stretches: weak absorptions around $3000 \mathrm{~cm}^{-1}$ $\mathrm{C}=\mathrm{O}$ stretch: $1668 \mathrm{~cm}^{-1}$

Aromatic $\mathrm{C}=\mathrm{C}$ stretch: $1600 \mathrm{~cm}^{-1}$ and $1506 \mathrm{~cm}^{-1}$

$\mathrm{NH}$ bending: shoulder at around $1530 \mathrm{~cm}^{-1}$

Aromatic CH OOP bending (para substituted ring): $810 \mathrm{~cm}^{-1}$

Fe-Cp stretch: $512 \mathrm{~cm}^{-1}$

No characteristic double anhydride band (in the ranges of $1800-1830 \mathrm{~cm}^{-1}$ and $1740-1775 \mathrm{~cm}^{-1}$ ) is observed in the spectrum of FcPA-xx. 
Appendix VI. Additional PXRD data related to transmetalation, and removal of $\mathrm{Fe}(0)$ from Fe@C with $\mathrm{HCl}$

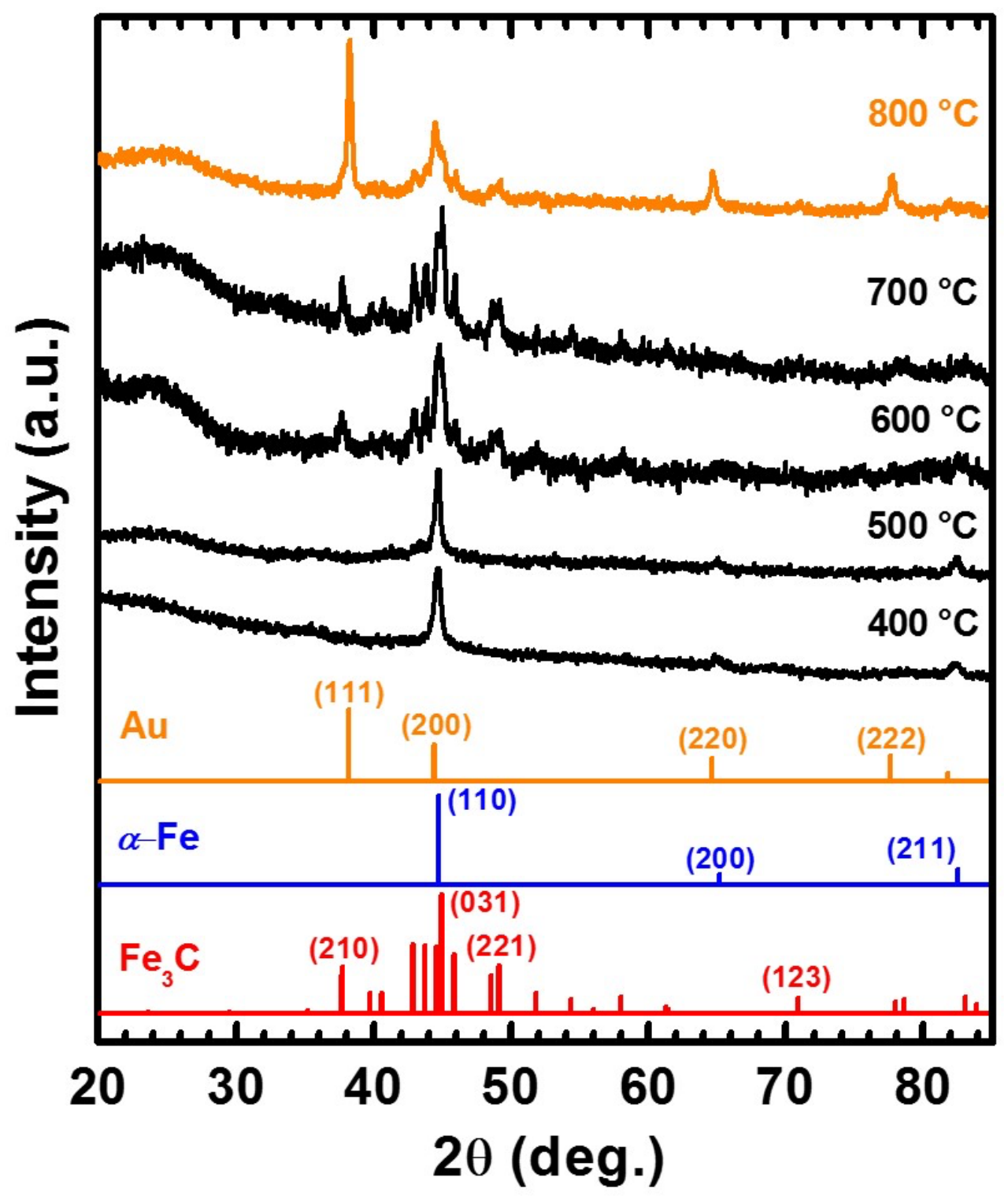

Figure S.7. Powder XRD after attempted transmetalation with a Au plating solution of FcPA-15 pyrolyzed at different temperatures, as shown. Note that $\mathrm{Fe}(0)$ is removed completely only from samples pyrolyzed at $800{ }^{\circ} \mathrm{C}$ (referred to as $\mathbf{F e} @ \mathbf{C}$ ). As noted here buy also in Figure 5 of the main article, $\mathrm{Fe}_{3} \mathrm{C}$ was produced at $\geq 600{ }^{\circ} \mathrm{C}$, and according to this Figure here, it survived the transmetalation process. 


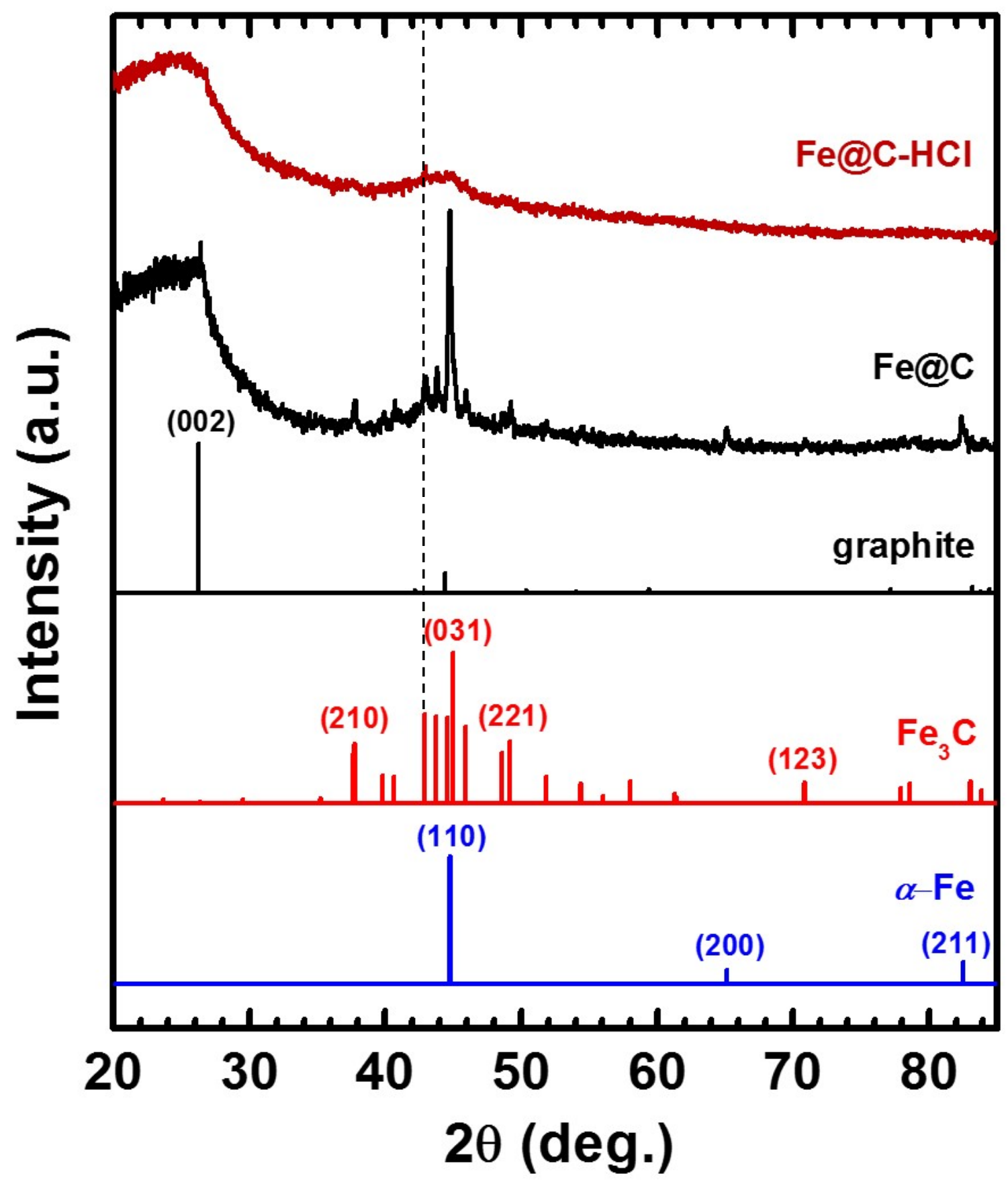

Figure S.8. Comparison of powder XRD data (PXRD) of as-prepared Fe@C and after treatment with a concentrated solution of $\mathrm{HCl}$ (see Experimental). The reflection designated by the dashed vertical line is attributed to surviving $\mathrm{Fe}_{3} \mathrm{C}$. 


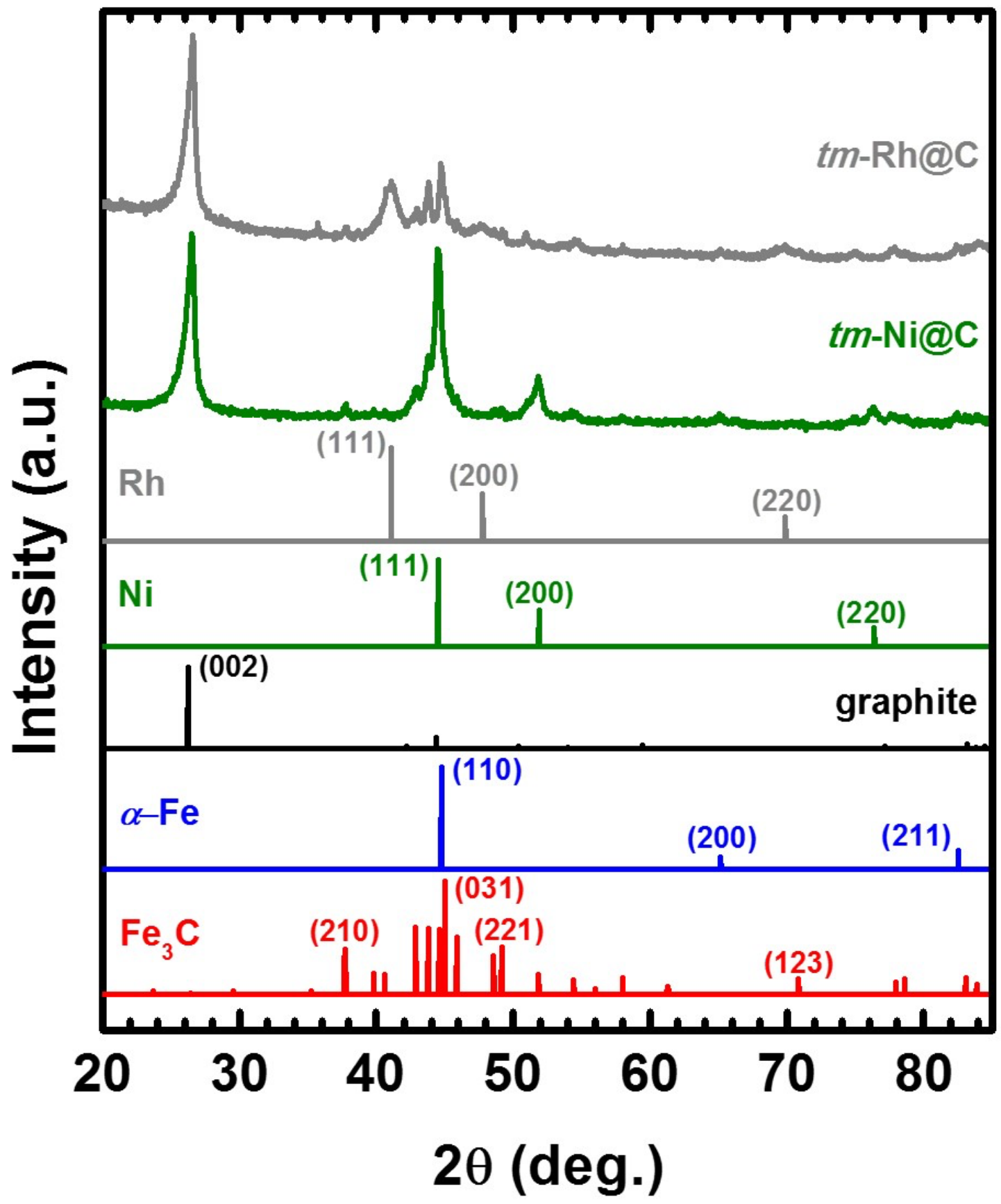

Figure S.9. Powder XRD data after transmetalation with $\mathrm{Ni}$ and $\mathrm{Rh}$ of FcPA-15 samples pyrolyzed at $1200{ }^{\circ} \mathrm{C}$ under $\mathrm{H}_{2}$, as shown. Both spectra are dominated by the (002) reflection of graphite and contain small amounts of $\mathrm{Fe}_{3} \mathrm{C}$. Owing to the overlap of the (111) reflection of $\mathrm{Ni}$ with the reflections from $\mathrm{Fe}_{3} \mathrm{C}$, reliable application of the Scherrer equation was possible only with the (111) diffraction of $\mathrm{Rh}$, whose crystallite size was calculated equal to $9 \pm 1 \mathrm{~nm}$. 


\section{Fe@C}
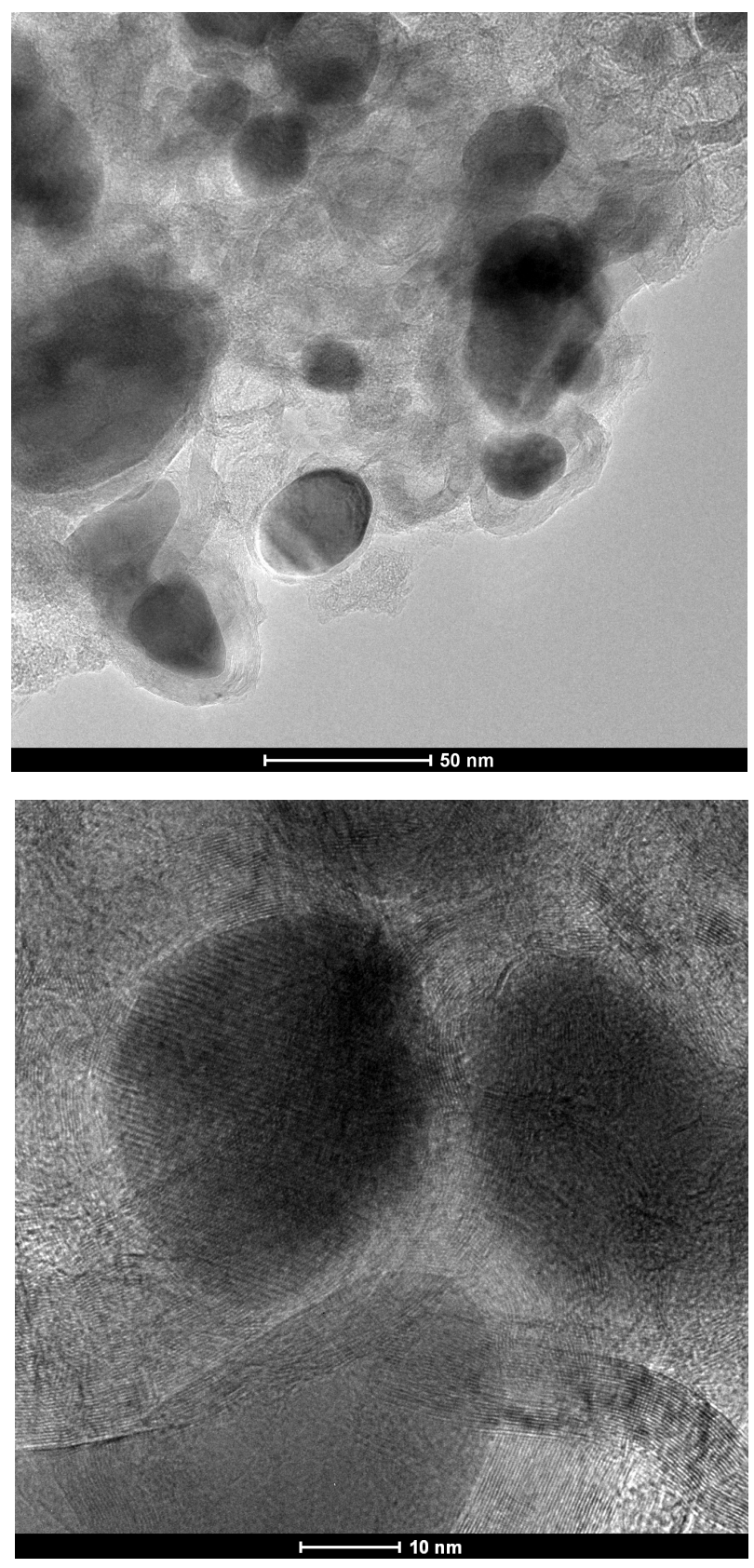

Fe@C after $\mathrm{HCl}$ treatment
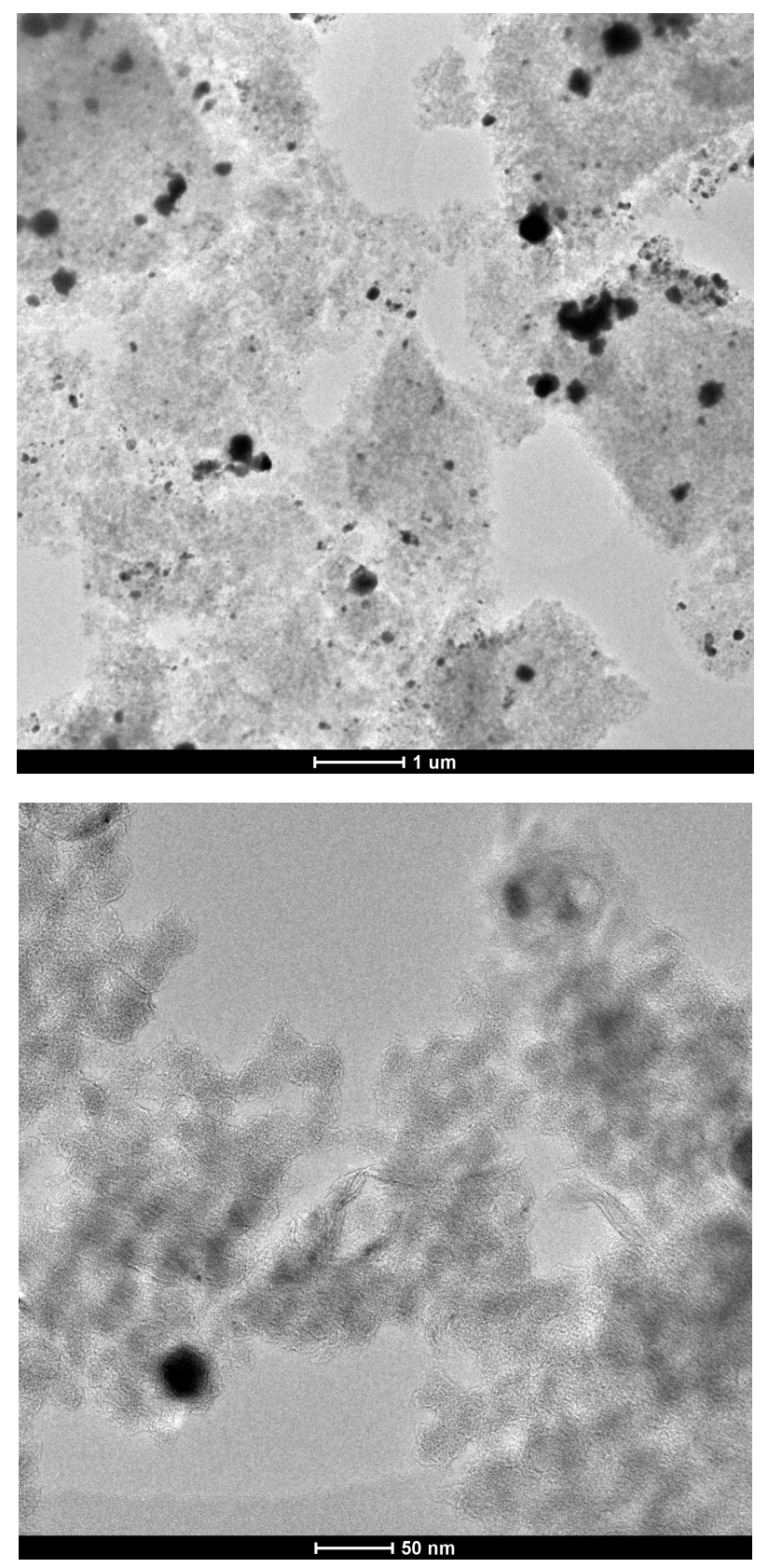

Figure S.10. TEM of samples as shown. Left: Fe@C. Left column top: Occasionally, ribbons swirl around and form pockets like those shrouding $\mathrm{Fe}(0)$ particles. Left Column bottom: Always $\mathrm{Fe}(0)$ particles are encased in ribbons. Right: Fe@C after treatment with concentrated aq. $\mathrm{HCl}$ at two magnifications. Consider these data together with the PXRD spectra of Fe@C before and after $\mathrm{HCl}$ treatment, shown in Figure S.8. (Continued on the next page.) 


\section{tm-Au@C}
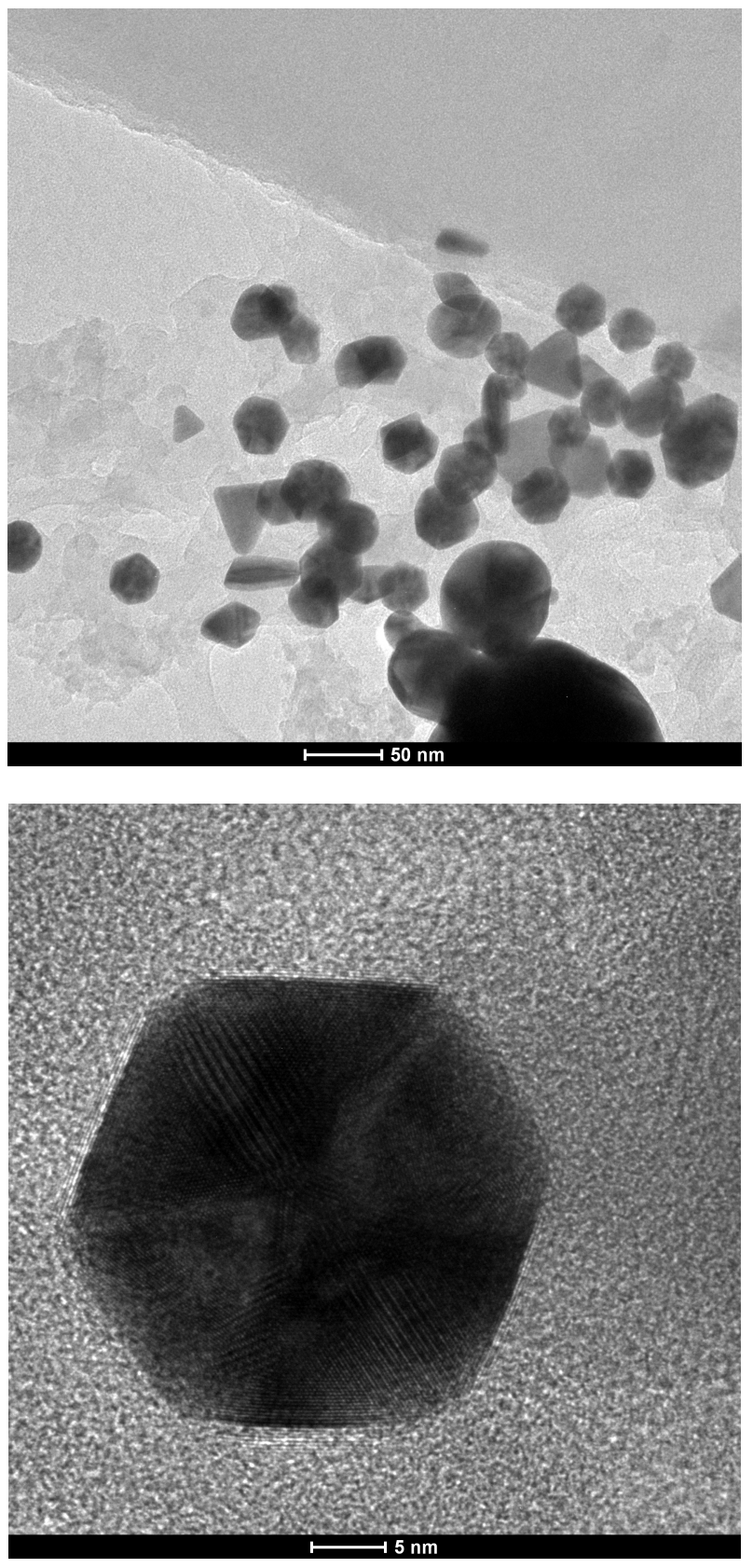

\section{tm-Pd@C}

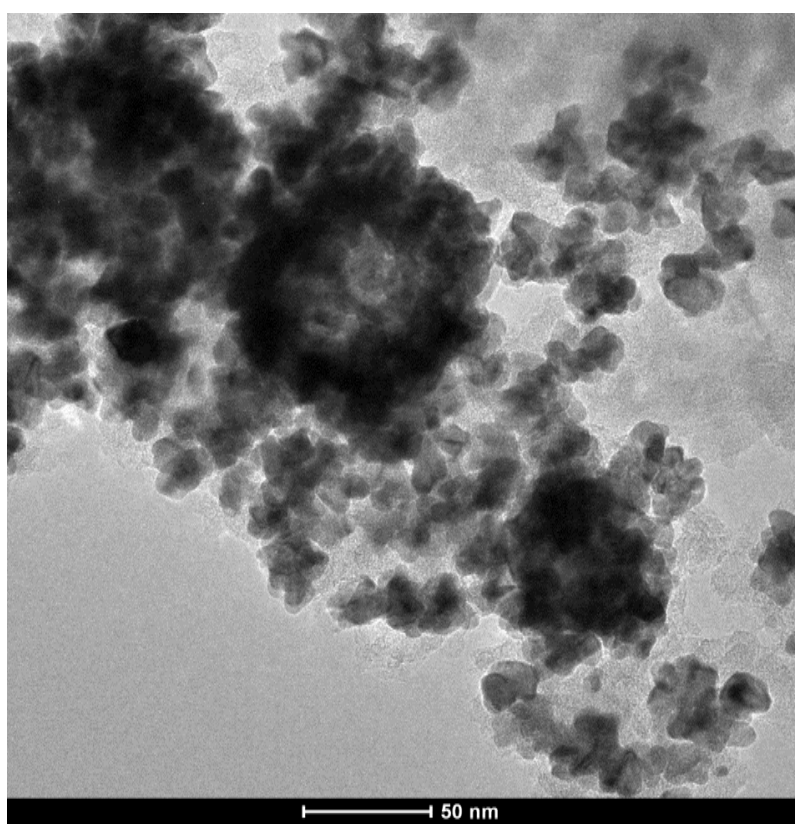

Figure S.10 (Continued). TEM of samples as shown. Nowhere in these post-transmetalation sample, new metallic nanoparticles could be associated with the interior of cages that contained $\mathrm{Fe}(0)$ in the Fe@C precursor. 


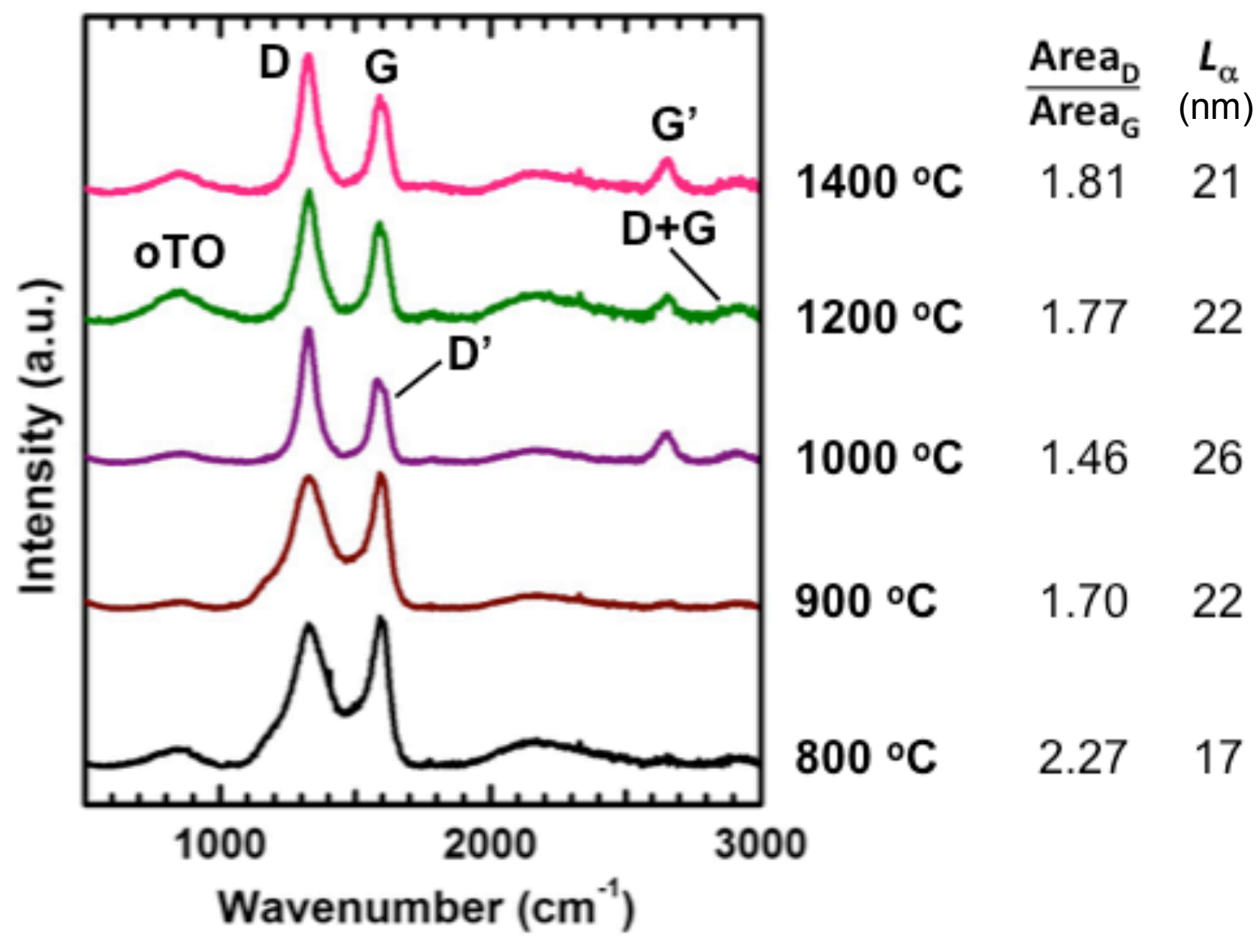

Figure S.11. Raman spectra after pyrolysis of FcPA-15 at different temperatures, as shown. All peak assignment according to Dresselhaus, M. S.; Dresselhaus, G.; Saito, R.; Jorio, A. "Raman spectroscopy of carbon nanotubes." Physics Reports 2005, 409, 47-99. The maxima of the peaks of interest are: D, $1326 \mathrm{~cm}^{-1} ; \mathrm{G}, 1592 \mathrm{~cm}^{-1}$. At higher resolution, the $\mathrm{D}^{\prime}$ peak appears as a shoulder at $1610 \mathrm{~cm}^{-1}$ in all spectra. The low-intensity, broad band at around $2150 \mathrm{~cm}^{-1}$ could not be assigned. The graphene layer stack height $\left(L_{\alpha}\right)$ was calculated using Knight's formula $\left(L_{a}(n m)=\left(2.4 \times 10^{-10}\right) \lambda_{\text {exc }}^{4}\left(\frac{A_{D}}{A_{G}}\right)^{-1}\right)$ from the ratio of the peak areas (cited on the right). Peak areas were calculated using deconvolution and Laurentian fit. $\lambda_{\text {exc }}$ is the wavelength of the laser, in our case $514.5 \mathrm{~nm}(2.41 \mathrm{eV})$. 
Appendix IX. Data from catalysis using Fe@C and tm-M@C as catalysts

Reaction:<smiles>Nc1cccc(C(=C(F)C(F)(F)F)C(F)(F)F)c1</smiles>

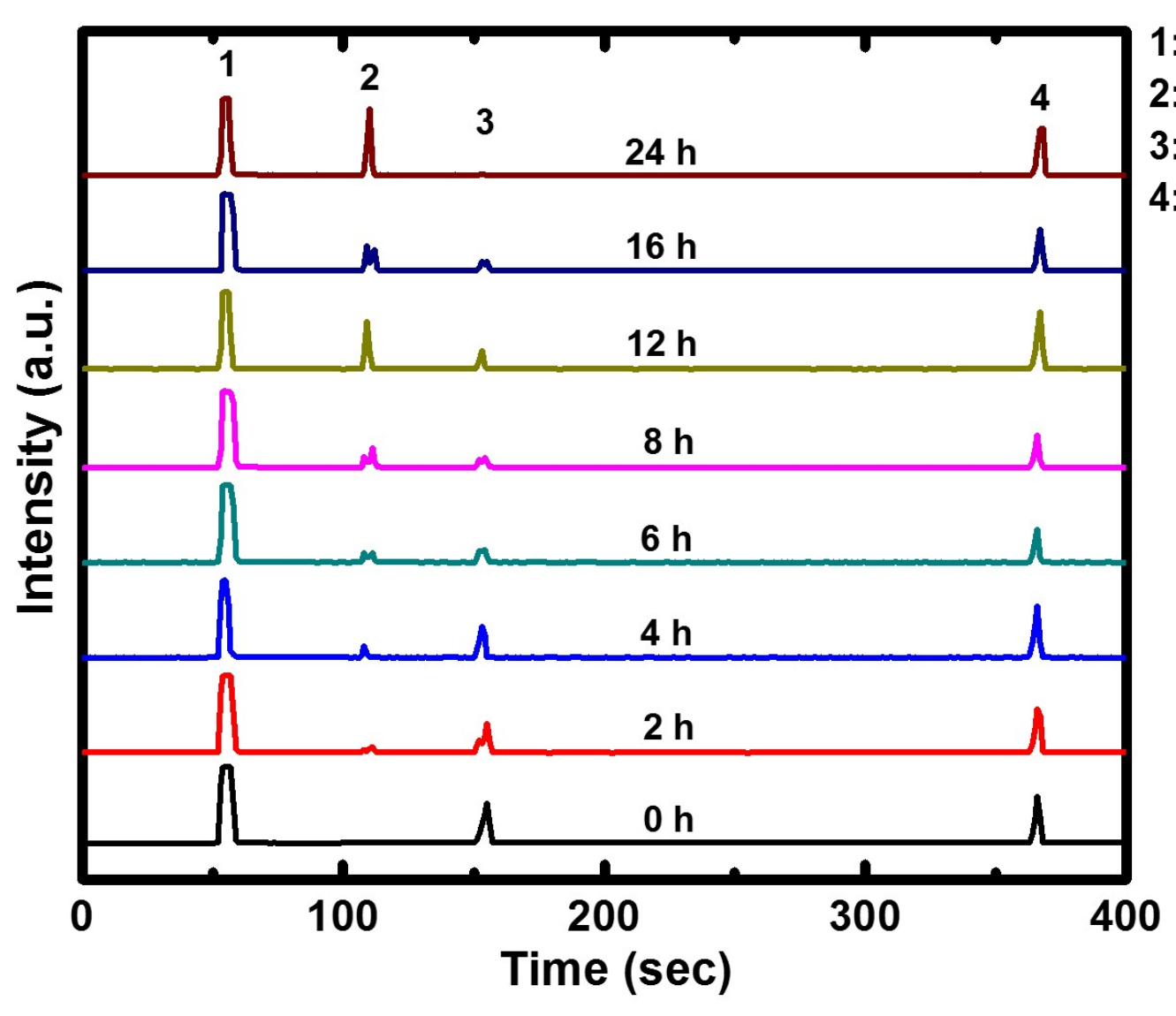

1: THF

2: aniline

3: nitrobenzene 4: hexadecane

Figure S.12. GC analysis of aliquots taken out during the $1^{\text {st }}$ Cycle of the reduction of nitrobenzene to aniline using a $\mathbf{F e} @ \mathbf{C}$ monolith as a catalyst. Results are plotted in Figure S.13. 


\section{Reaction:}

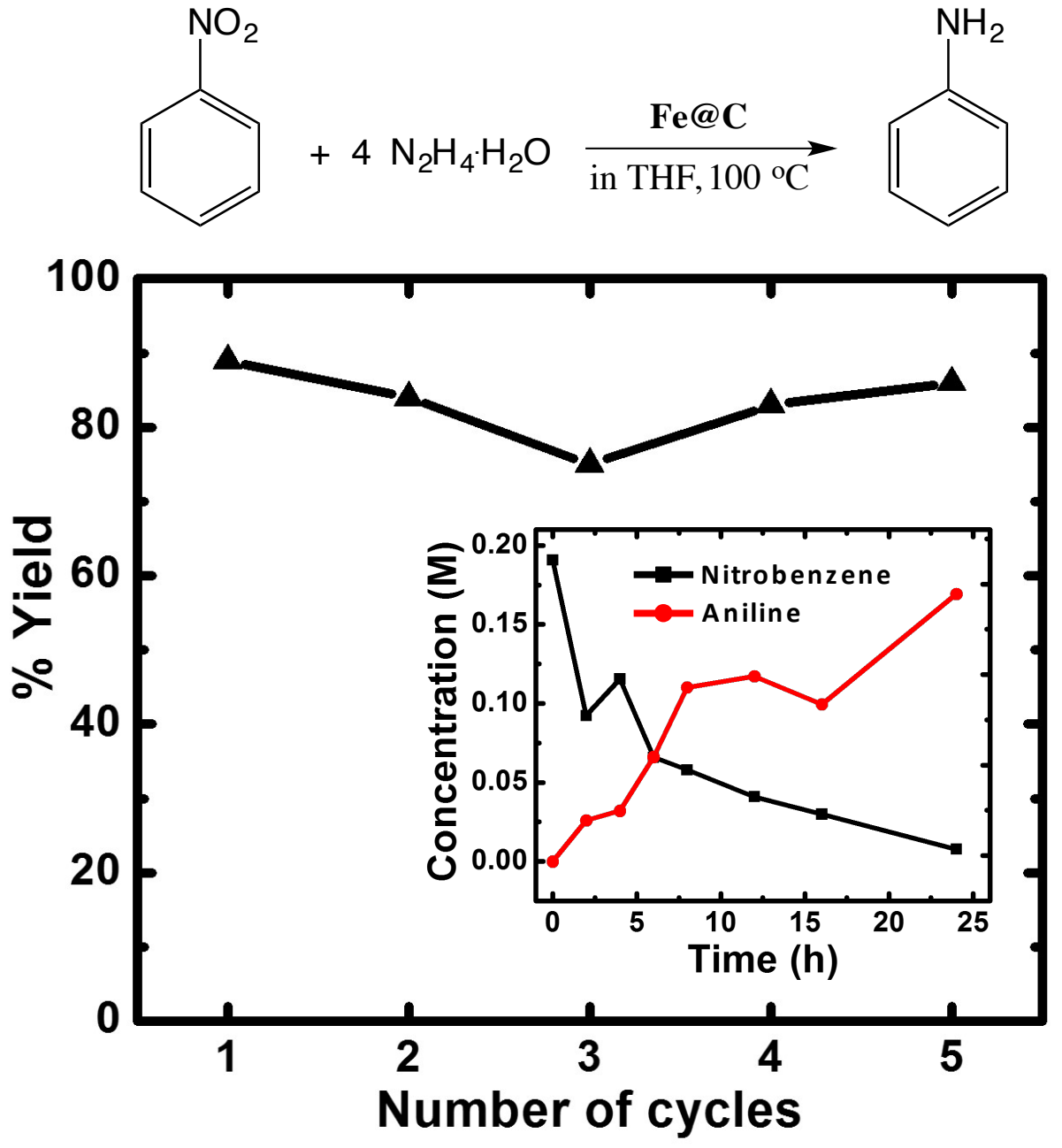

Figure S.13. Reduction of nitrobenzene to aniline using a $\mathbf{F e} @ \mathbf{C}$ monolith as a catalyst. Inset: Evolution of reactant and product concentrations in a $24 \mathrm{~h}$ period $\left(1^{\text {st }} \mathrm{Cycle}\right)$. Data from Figure S.12. 


\section{Reaction:}
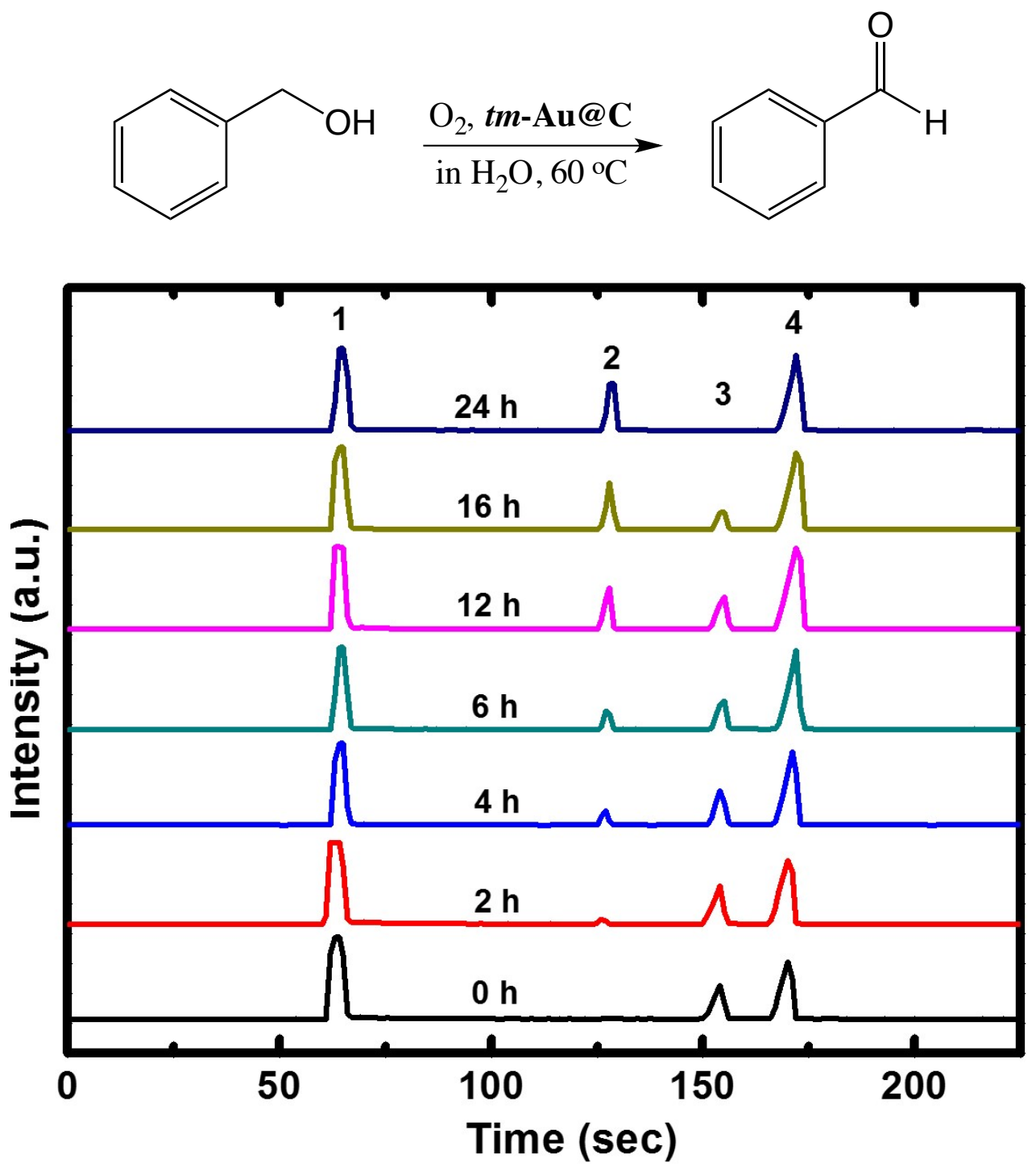

1: ether

2: benzaldehyde

3: benzyl alcohol

4: acetophenone

Figure S.14. GC analysis of aliquots taken out during the $1^{\text {st }}$ Cycle of the oxidation of benzyl alcohol to benzaldehyde using a tm-Au@C monolith as catalyst. Results are plotted in Figure S.15. 
Reaction:
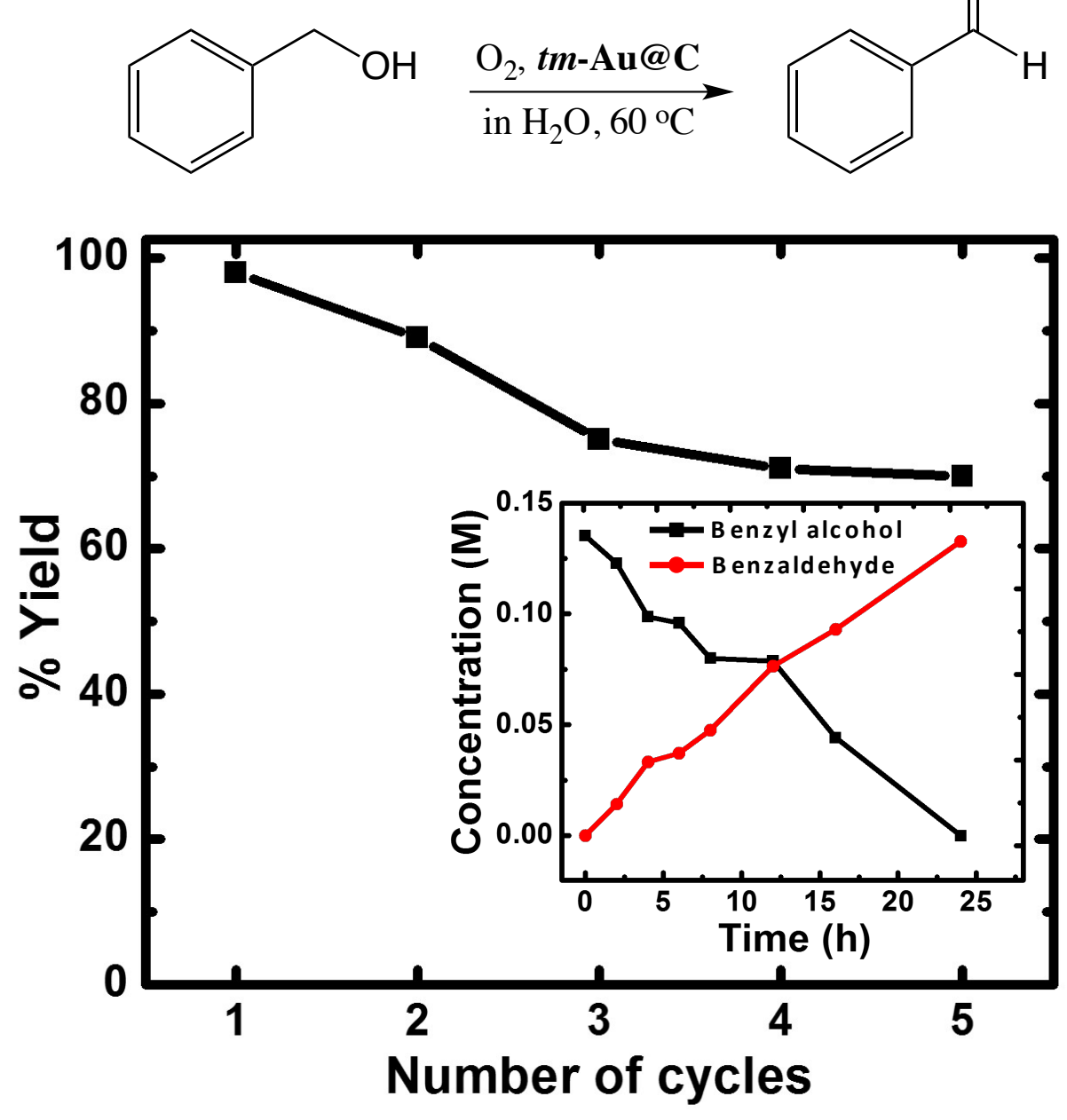

Figure S.15. Oxidation of benzyl alcohol to benzaldehyde using a tm-Au@C monolith as a catalyst. Inset: Evolution of reactant and product concentrations in a $24 \mathrm{~h}$ period $\left(1^{\text {st }}\right.$ Cycle). Data from Figure S.14. 


\section{Reaction:}

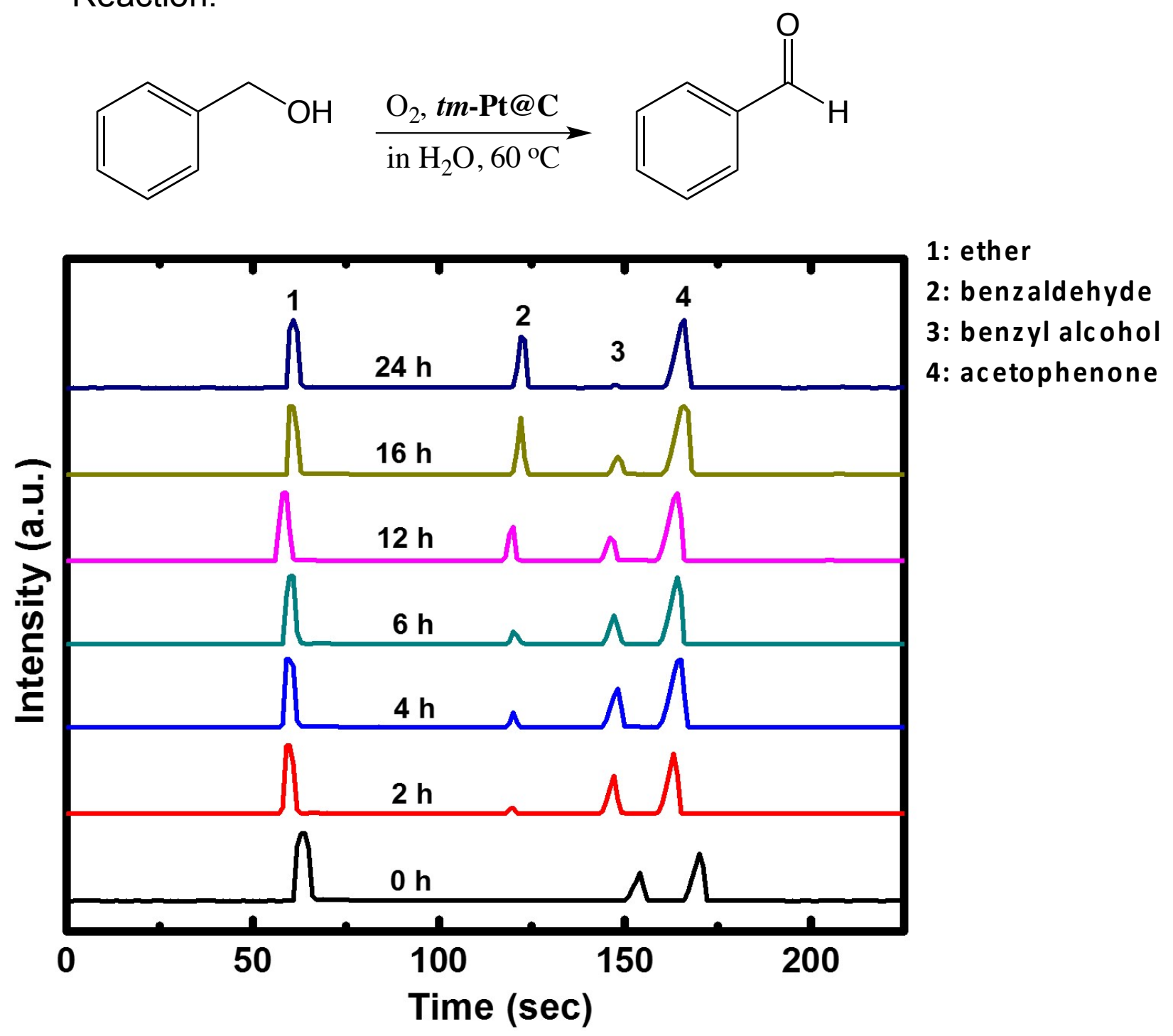

Figure S.16. GC analysis of aliquots taken out during the $1^{\text {st }}$ Cycle of the oxidation of benzyl alcohol to benzaldehyde using a tm-Pt@C monolith as catalyst. Results are plotted in Figure S.17. 
Reaction:<smiles>OCc1ccccc1</smiles>
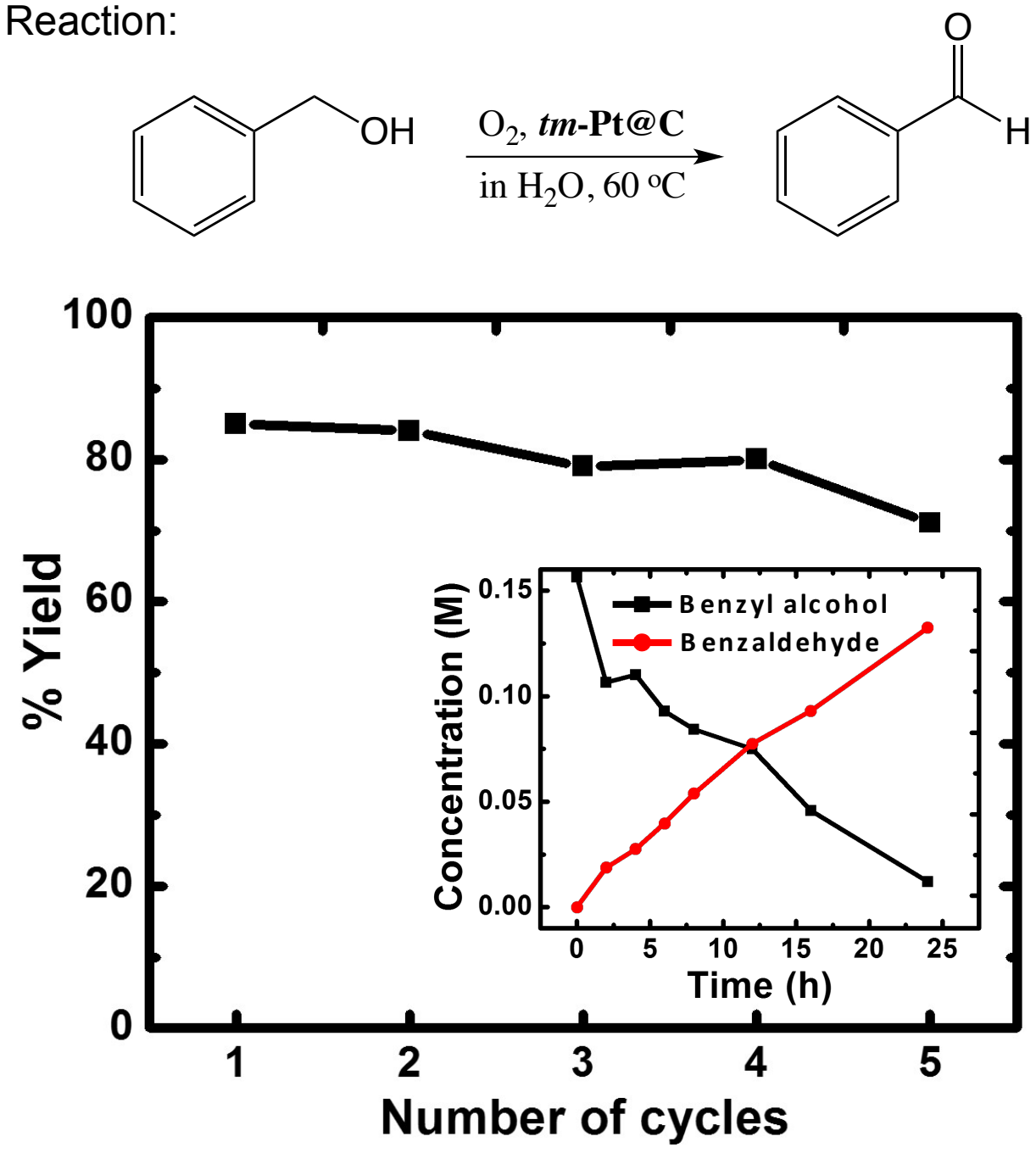

Figure S.17. Oxidation of benzyl alcohol to benzaldehyde using a tm-Pt@C monolith as catalyst. Inset: Evolution of reactant and product concentrations in a $24 \mathrm{~h}$ period $\left(1^{\text {st }}\right.$ Cycle). Data from Figure S.16. (Note the similarity of the data with using $\mathbf{t m - A u} @ \mathbf{C}$ as a catalyst in Figure S.15.) 


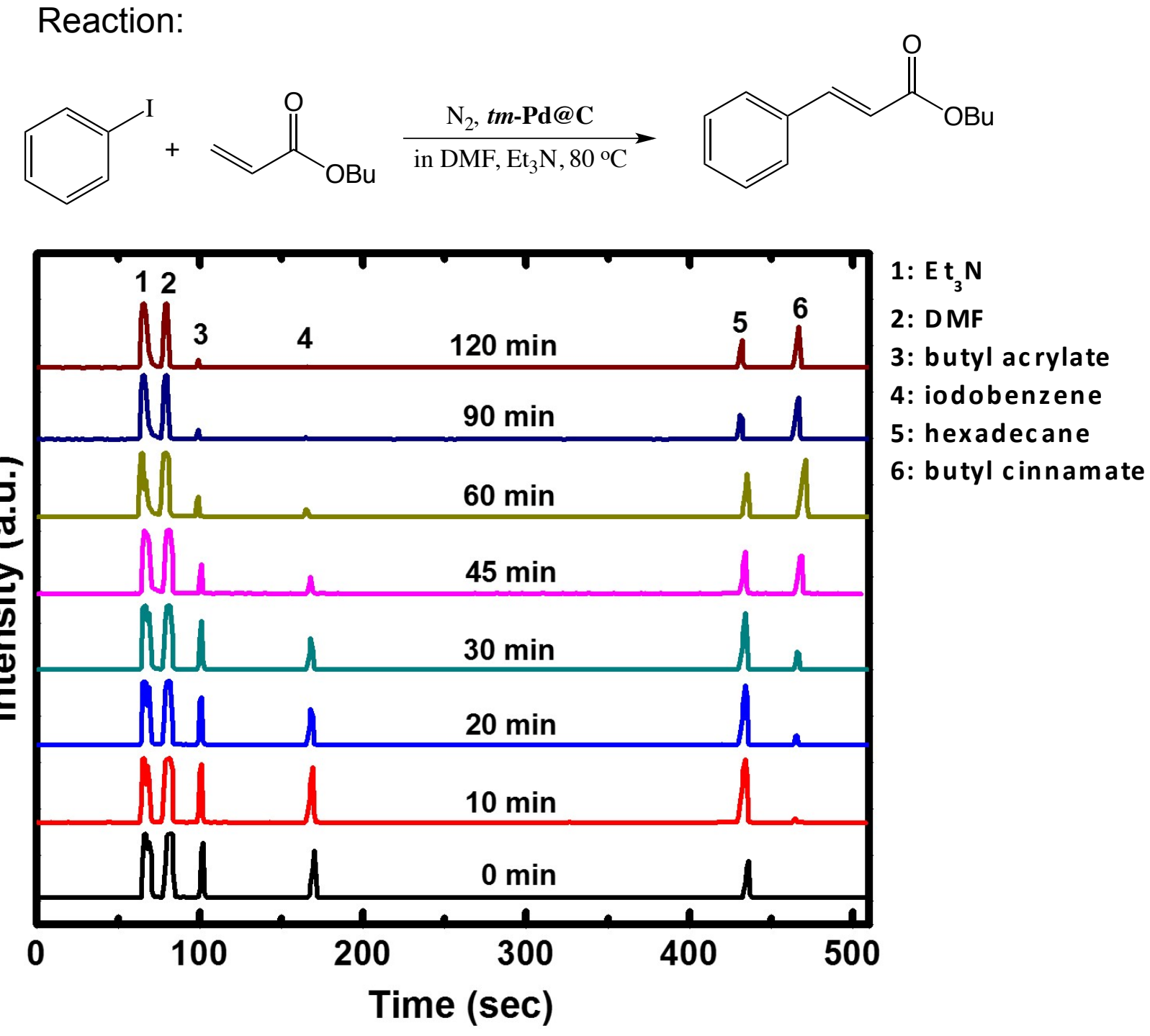

Figure S.18. GC analysis of aliquots taken out during the $1^{\text {st }}$ Cycle of the Heck coupling of iodobenzene and butyl acrylate towards butyl cinnamate using a $\mathbf{t m}-\mathbf{P d} @ \mathbf{C}$ monolith as a catalyst. Results are plotted in Figure S.19. 


\section{Reaction:}
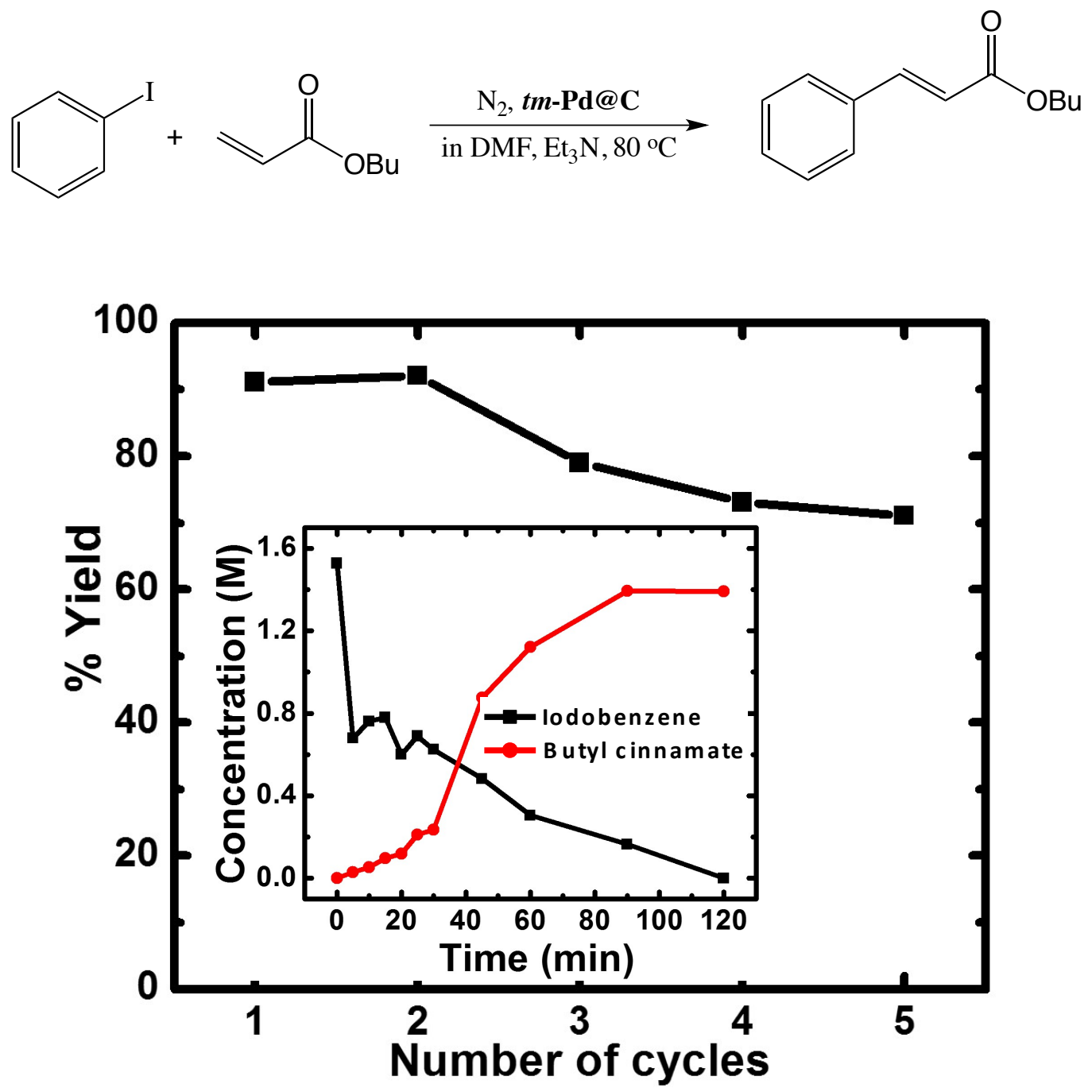

Figure S.19. Heck coupling of iodobenzene and butyl acrylate towards butyl cinnamate using a tm-Pd@C monolith as a catalyst. Inset: Evolution of reactant and product concentrations in a $2 \mathrm{~h}$ period $\left(1^{\text {st }}\right.$ Cycle $)$. Data from Figure S.18. 


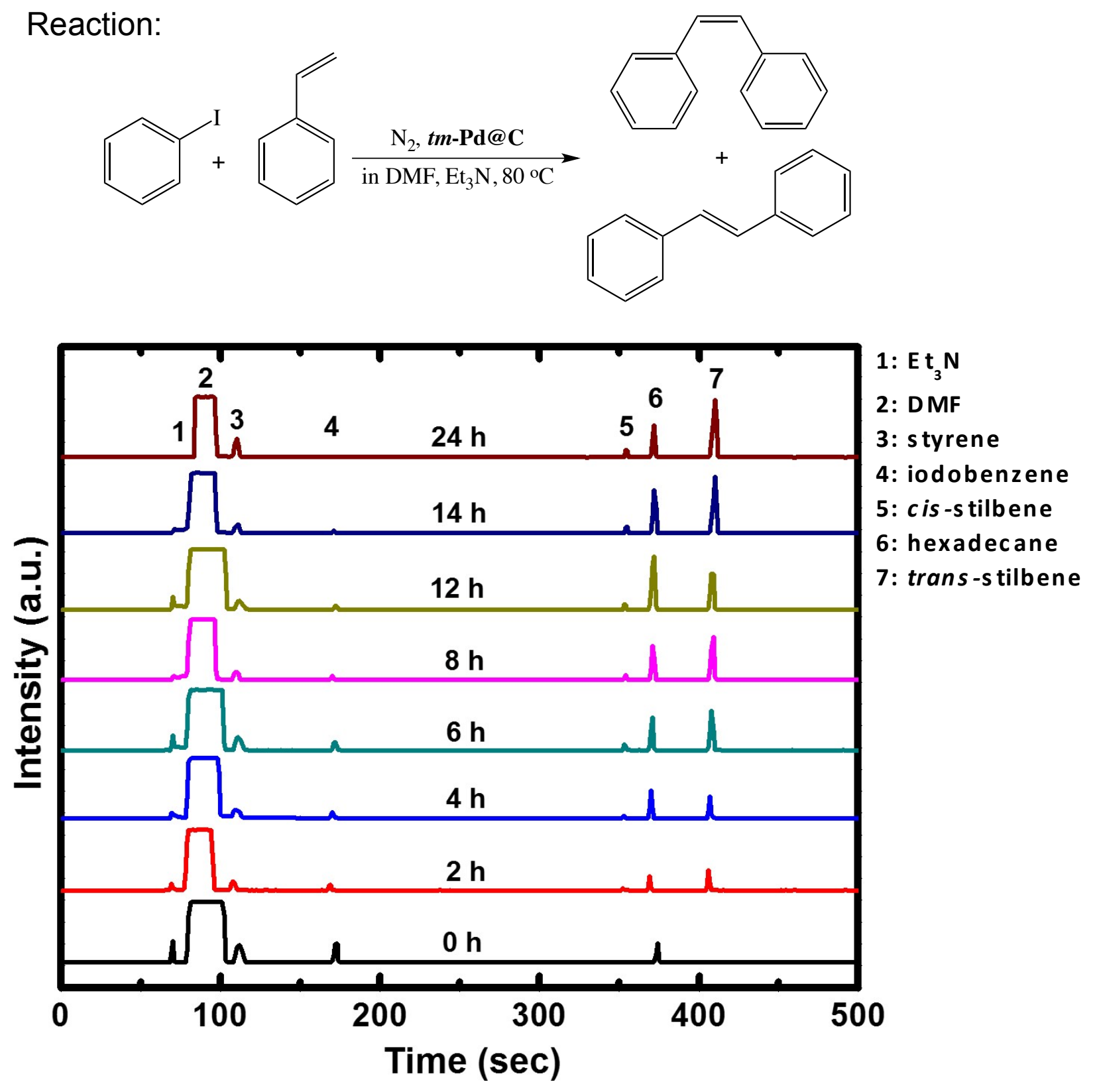

Figure S.20. GC analysis of aliquots taken out during the $1^{\text {st }}$ Cycle of the Heck coupling of iodobenzene and styrene towards cis- and trans-stilbene using a tm-Pd@C monolith as a catalyst. Results are plotted in Figure S.21. 


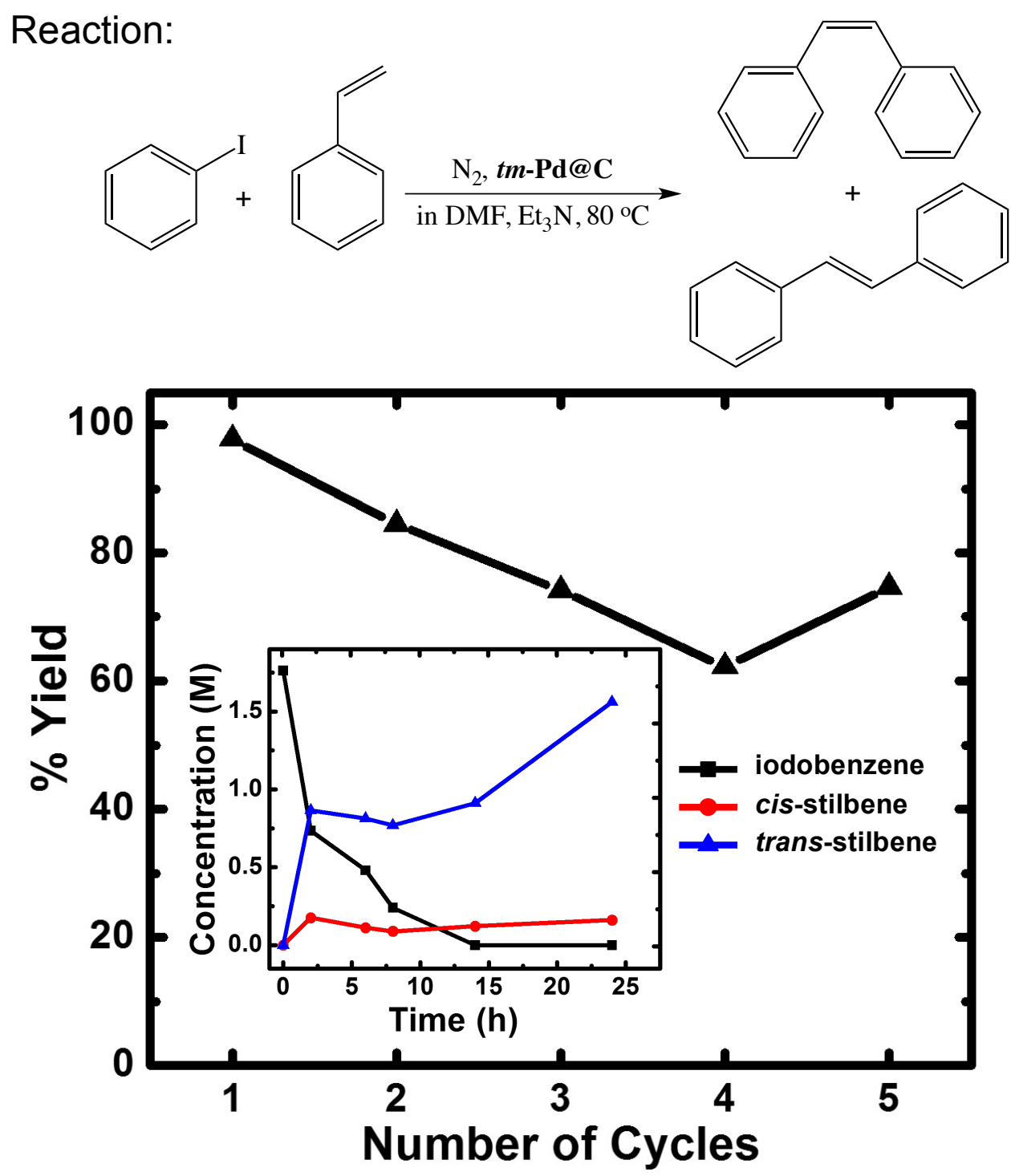

Figure S.21. Heck coupling of iodobenzene and styrene towards cis- and trans-stilbene using a tm-Pd@C monolith as a catalyst. Inset: Evolution of reactant and product concentrations in a $24 \mathrm{~h}$ period $\left(1^{\text {st }}\right.$ Cycle). Data from Figure S.20. 